\title{
Analysis on Deformation and Stress Characteristics of a Multibraced Pit-in-Pit Excavation in a Subway Transfer Station
}

\author{
Xin Shi $\mathbb{D}^{1,2}$ Chuanxin Rong $\mathbb{D}^{1,},{ }^{1,2}$ Hua Cheng, ${ }^{2}$ Linzhao Cui, ${ }^{3}$ Bin Wang $\mathbb{D}^{2}{ }^{2}$ \\ and Shicheng Sun ${ }^{2}$ \\ ${ }^{1}$ State Key Laboratory of Mining Response and Disaster Prevention and Control in Deep Coal Mine, \\ Anhui University of Science and Technology, Huainan 232001, China \\ ${ }^{2}$ School of Civil Engineering and Architecture, Anhui University of Science and Technology, Huainan 232001, China \\ ${ }^{3}$ Anhui Water Resources Development Co., Ltd., Bengbu 233000, China \\ Correspondence should be addressed to Chuanxin Rong; rongcx@ustc.edu
}

Received 8 June 2020; Revised 12 July 2020; Accepted 11 August 2020; Published 31 August 2020

Academic Editor: Xue Zhang

Copyright (C) 2020 Xin Shi et al. This is an open access article distributed under the Creative Commons Attribution License, which permits unrestricted use, distribution, and reproduction in any medium, provided the original work is properly cited.

\begin{abstract}
As an important part of subway transfer station construction, pit-in-pit (PIP) excavation has always been a key object of monitoring and control. In this study, taking the PIP excavation project of Hefei metro line 4 and line 7 transfer station as the background, combined with on-site monitoring and numerical simulation, the variation law of lateral wall displacement, ground surface settlement, and strut force during the PIP excavation were analyzed. The results showed that the maximum lateral deformation of the pile caused by the excavation of the external pit accounted for $80 \%-90 \%$ of the total deformation and the surface settlement accounted for $70 \%$ of the total settlement. The excavation of the inner pit only made the maximum lateral wall displacement of the outer pit and the surface settlement behind the wall increase slightly, the growth rate tended to zero, and the maximum lateral deformation depth was all above the excavation surface, which indicated that, for this project, the inner excavation had little effect on the outer pit retaining structure. In addition, the increased exposure time of the soil at the bottom of the pit and the presence of the corner effect will cause the further development of the structure displacement and the surface settlement. Based on strut force measurements, using the tributary area load distribution procedure, it was obtained that $0.3 \gamma H_{e}$ was used as the upper limit index of strut force in the region, where $\gamma$ is the weight of the soil and $H_{e}$ is the excavation depth of the foundation pit. The research conclusions were helpful for the construction and sustainable development of the PIP project.
\end{abstract}

\section{Introduction}

With the continuous development of the social economy and increasing urban traffic pressure, many large and medium-sized cities have to build underground transportation networks to alleviate surface traffic pressure. The subway transfer station serves as a node of the underground transportation network, and its special supporting structure in the PIP will increase the construction risk. The study of the degree of soil disturbance and the deformation law of the supporting structure in the PIP excavation is of great significance for the protection of the surrounding environment.

The apparent pressure diagram (APD) proposed by Terzaghi [1] and Peck [2] is widely used in sand, hard- cracked clay, and soft-to-medium clay for braced excavations to estimate the magnitude and distribution of strut loads. Based on a finite element analysis, some scholars have studied the influence of the deep excavation on existing structures [3], the basal heave stability for excavation in spatial variable soils [4], and the distribution of axial forces under different wall stiffnesses in different soil layers $[5,6]$. Wang et al. [7] proposed a braced excavation back analysis method that considered the three-dimensional effect based on the plane-strain assumption. Mohamed et al. [8] used the finite difference code to simulate a three-dimensional excavation and compared it with measured data. In addition, Mohamed et al. also briefly remarked on the prediction of excavation behavior by means of $2 \mathrm{D}$ compared with $3 \mathrm{D}$ 
numerical analysis results. Rich data and achievements have also been provided by experimental studies [9, 10], and field measurement analyses of excavation cases [11-20] also enable the further development of foundation pit excavation research.

The above studies are based on the fact that a foundation pit is excavated to a certain depth. Considering the requirements of building foundation structures, elevator shafts, basements, and subway transfer stations, the inside of the foundation pit often needs to be excavated twice or even multiple times, and its cross-sectional form is difficult to guarantee the square rule. The phenomenon of difference in depth inside the foundation pit is becoming more and more common. Combining the theory of ground loss with empirical equations, Sun et al. [21] proposed a prognoses method on curve and the maximum value of ground subsidence which is suitable for Beijing area. And, based on the hypothesis of theoretical excavation line and function mass, the mechanism of difference in surrounding strata deformation was proposed. Hou et al. [22] adopted the hardening-soil finite element model with unloaded soil to study the influence of the ratio $\beta$ of internal depth to bottom width on the supporting structure and soil deformation. Based on the limited equilibrium theory and the hypothesis of planar sliding plane, Han et al. [23] deduced four formulas for calculating passive earth pressure with cohesion force and different shapes of sliding soil mass taken into account, and corresponding mathematical expressions of shear failure angles are given.

The above studies on PIP excavation are based on specific assumptions using theoretical and numerical analysis methods. However, there are few studies on detailed field measurement data during the entire construction process. The research of the field measured data is often more representative than the theoretical and numerical analysis, and the research results are more instructive to the construction of the PIP project.

In this study, taking a PIP excavation in a subway transfer station in Hefei as the background, the lateral wall displacement, ground settlement, and strut force during the whole construction process were monitored in detail. Through the analysis of monitoring data and comparison with numerical simulation results, the spatiotemporal evolution of the support structure deformation and ground settlement during PIP excavation is discussed. As the capital city of Anhui Province in southeastern China, Hefei has multiple subway lines under simultaneous construction. The impact assessment of subway construction on the surrounding environment is particularly important [24]. There are few studies on the PIP excavation in this area, and it is hoped that the results of this study will provide guidance for the follow-up subway construction.

\section{Project Overview}

2.1. Site. The excavation project used in this study was the transfer station of two orthogonally intersecting subway lines. Figure 1 shows a plan view of this site. The project for this station consisted of two parts. The outer excavation is the pit of the No. 4 line (first construction), the excavation plane is $261.8 \mathrm{~m}$ long $\times 21.9 \mathrm{~m}$ wide, and the excavation depth is $17.9 \mathrm{~m}$. The inner excavation is the pit of the No. 7 line (second construction), the excavation plane is $176.9 \mathrm{~m}$ long $\times 23.1 \mathrm{~m}$ wide, and the excavation depth is $7.9 \mathrm{~m}$. Because the south end of the No. 7 line intersects the standard section of the No. 4 line, a nonrectangular excavation surface is created at the north side of the intersection, which makes the design and construction of the PIP support structure more difficult.

The excavation examined in this study used the segmental earthwork transfer excavation method, and the excavation sequence is shown in Figures 1 and 2 . The horizontal section length is based on the structural section and is controlled between 15 and $30 \mathrm{~m}$. The vertical stratification is divided according to the mechanical excavation ability and the strut positions. The outer excavation is divided into four layers from top to bottom. The construction was conducted from the two ends to the middle, and the excavation was stopped when excavated to the intersection position. The inner excavation was divided into seven floors from top to bottom, and construction began from the intersection and moved from the two ends to the middle.

2.2. Geology. Prior to the construction, the soil layer distribution of the site was obtained by drilling a pit location. There were six strata at the excavation site of the station: fill, medium clay, stiff clay, fully weathered sandy mudstone, strong weathered sandy mudstone, and moderately weathered sandy mudstone. The final excavation position of the outer pit was located in the stiff clay layer, and the final excavation position of the inner pit was located in the strong weathered sandy mudstone. The soil profile of the station intersection is shown in Figure 3. Before the PIP excavation, the geological survey personnel obtained the basic physical parameter indexes of the typical strata within the scope of the project through borehole sampling and laboratory tests, as shown in Table 1.

The groundwater of this station consisted primarily of perched water and bedrock fissure water. The perched water was primarily distributed in the surface silty clay filling. The bedrock fissure water was primarily distributed in the fully weathered sandy mudstone and the strongly weathered sandy mudstone, and the single hole water inflow was generally less than $10 \mathrm{~m}^{3} / \mathrm{d}$. The water richness was between extremely poor and poor.

2.3. Construction Sequences. Figure 4 shows a plan view and two cross-sectional views of the north-south direction at the intersection of the two subway lines. Due to the use of the segmental earthwork transfer excavation method, in the excavation sequence shown in Figures 1 and 2, the outer excavation (line 4) had only the crossover portion of the soil during the excavation of the intersection, and the excavation of the east and west sides was completed, while the inner excavation (line 7) was not excavated. Three layers of concrete struts were used on the east and west sides of the intersection in the outer pits. Because the excavation depth 


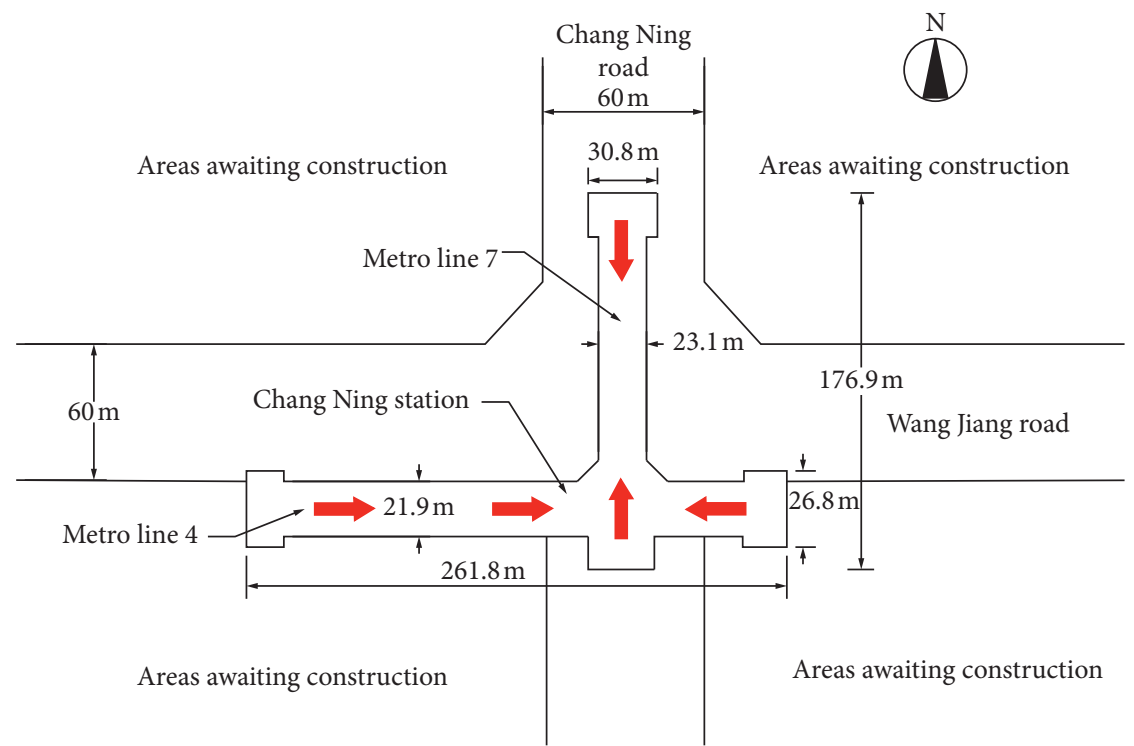

$\Rightarrow$ The excavation direction

FIgURe 1: Plan view of site.

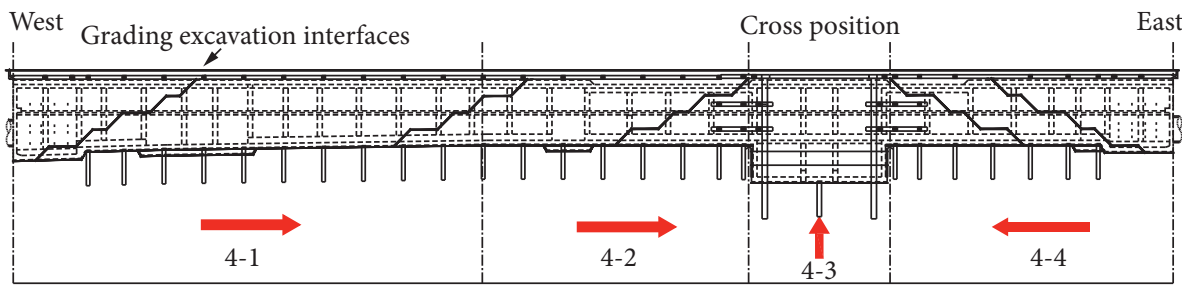

The excavation direction of line 4

FIgURE 2: The profile of the excavation sequence.

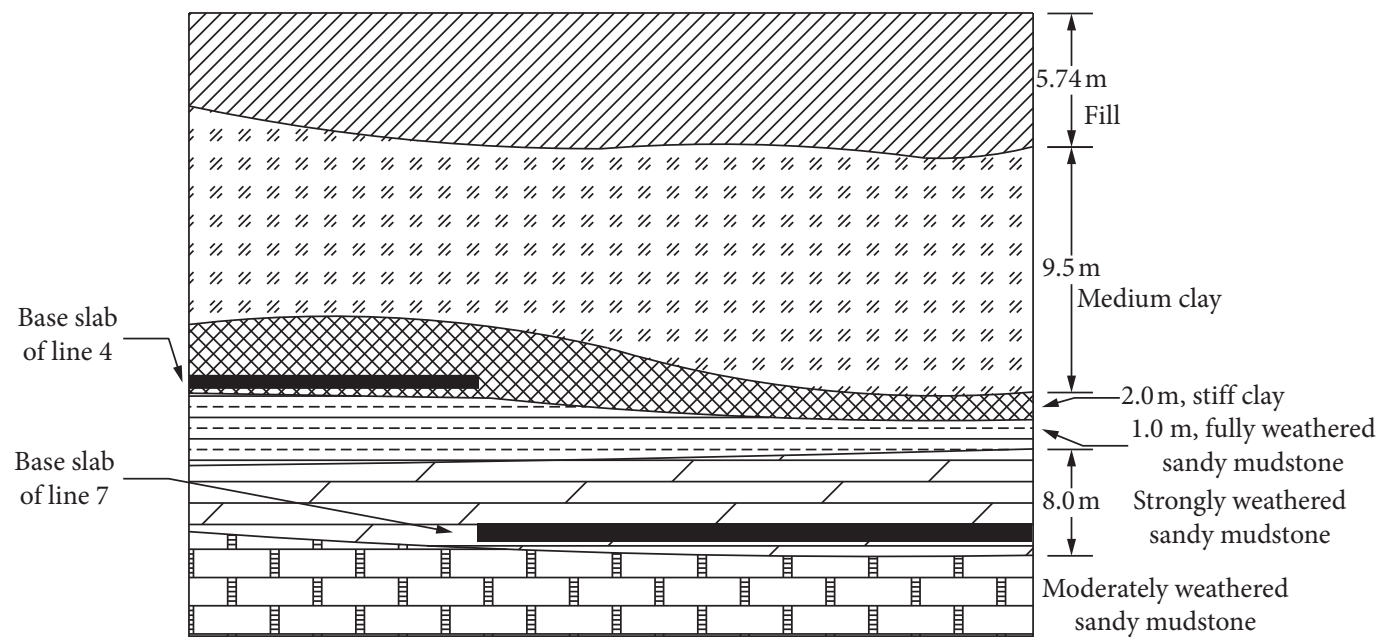

FIgURE 3: Soil profile of the intersection.

of the southern end was different from that of the standard section, three concrete struts and two steel bracings with an external diameter of $609 \mathrm{~mm}$ were used on the south side of the intersection, and four concrete struts were used to support the north side of the intersection. The concrete strength grade was C30, and the steel was selected from 
TABLE 1: Soil layer properties within the site.

\begin{tabular}{lccccc}
\hline Soil name & $\begin{array}{c}\text { Unit weight of soil } \\
\left(\mathrm{kN} / \mathrm{m}^{3}\right)\end{array}$ & $\begin{array}{c}\text { Effective } \\
\text { cohesion }(\mathrm{kPa})\end{array}$ & $\begin{array}{c}\text { Effective friction } \\
\text { angle }\left(^{\circ}\right)\end{array}$ & $\begin{array}{c}\text { In situ lateral earth } \\
\text { pressure coefficient }\end{array}$ & $\begin{array}{c}\text { Compressible } \\
\text { modulus }(\mathrm{MPa})\end{array}$ \\
\hline Fill & 18.8 & 10 & 8 & 0.65 & 8 \\
Medium clay & 19.5 & 55 & 14 & 0.39 & 12 \\
Stiff clay & 19.9 & 36 & 16 & 0.38 & 13 \\
$\begin{array}{l}\text { Fully weathered sandy } \\
\text { mudstone }\end{array}$ & 19.0 & 35 & 20 & 0.38 & 27.86 \\
$\begin{array}{l}\text { Strongly weathered sandy } \\
\text { mudstone }\end{array}$ & 21.3 & 45 & 25 & & 33.64 \\
$\begin{array}{l}\text { Moderately weathered } \\
\text { sandy mudstone }\end{array}$ & 21.7 & 50 & & & \\
\hline
\end{tabular}

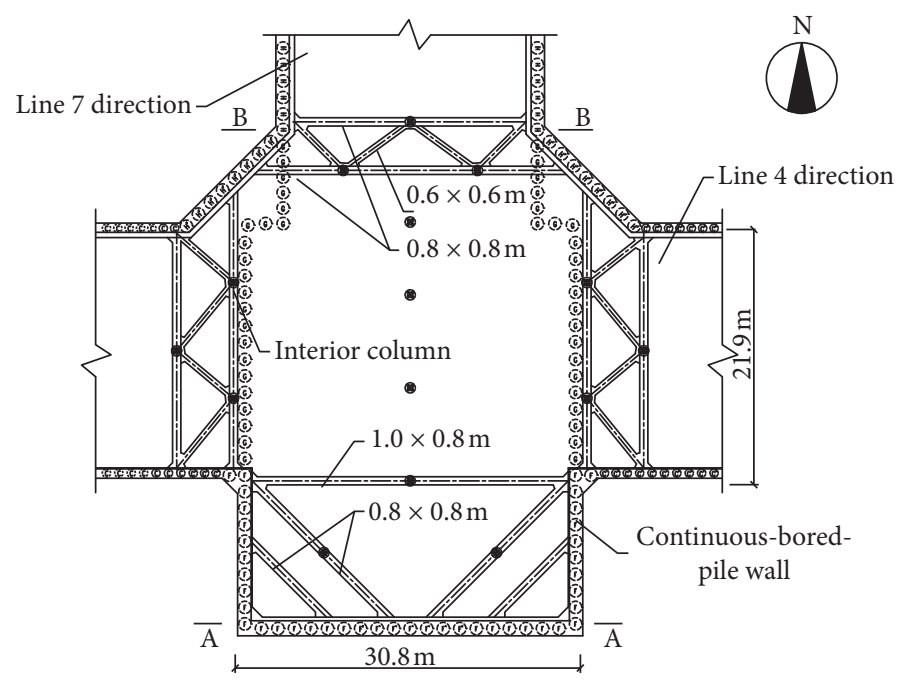

(a)

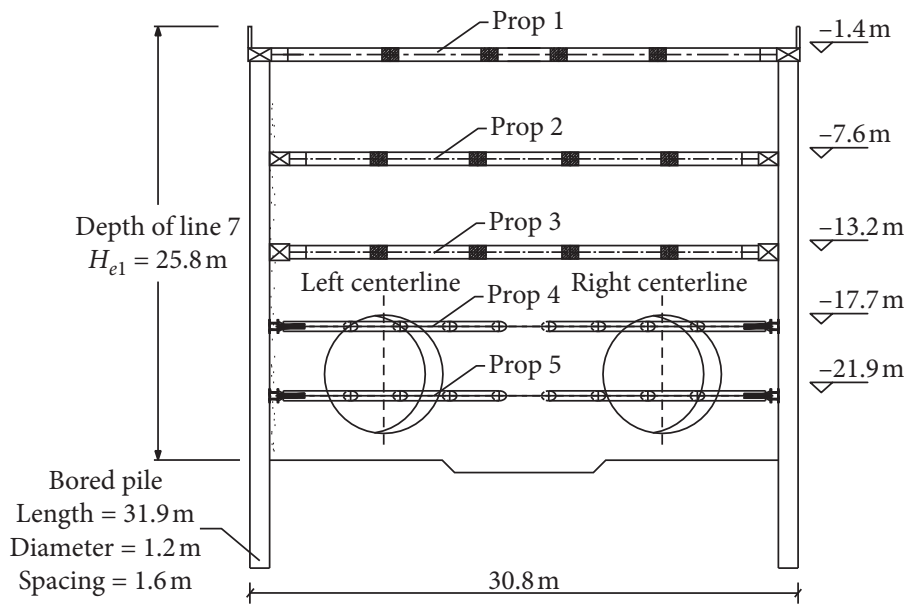

(b)

Figure 4: Continued. 


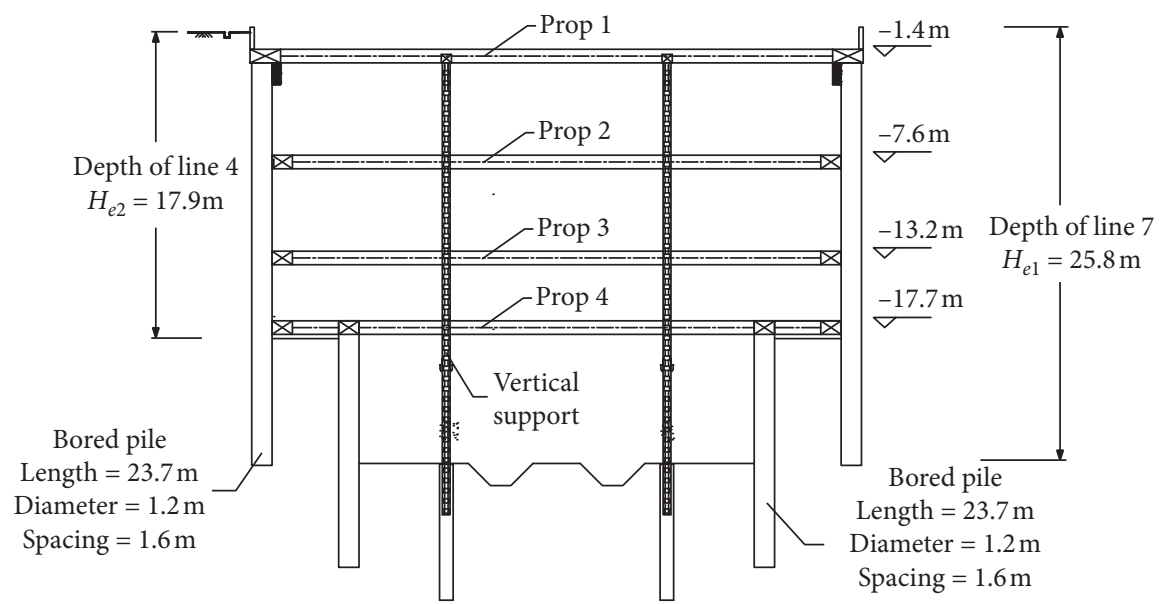

(c)

Figure 4: Plan view at the intersection of the two subway lines (a) and the two cross sections: A-A (b) and B-B (c).

ordinary carbon steel Q235. The support distribution, support material, and support section geometry parameters in the four directions are summarized in Table 2.

The excavation at the intersection was very deep, the shape of the plane was irregular, and the strut distribution was complicated. Therefore, the construction of this portion of the structure was considered to be a risky link. The detailed construction stages of the intersections are summarized in Table 3. Because the excavation was conducted in stages, for the same layer of support at the intersection, the support in different directions differed in the installation time. For ease of analysis, Table 3 gives a uniform support installation time as a reference. The outer excavation was divided into east-west sides (first excavation) and intersection position (secondary excavation), which were divided into four layers of progressive construction according to the foregoing. To facilitate the study of the deformation characteristics of the excavation during different stages, the construction of outer excavation was divided into stage II and stage III, which represented the east-west excavation and the cross-position excavation, respectively.

\section{On-Site Monitoring}

3.1. Layout of Monitoring Points. By setting monitoring points at different positions in the four directions of the intersection, the lateral wall displacement, strut forces, and surface settlement during the different excavation stages were analyzed. To facilitate an analysis of the measurements, a uniform measuring point number was adopted, and the arrangement and numbering of the measuring points at the intersecting positions are as shown in Figure 5.

The depth displacement of the pile body is reflected by the angle change of the inclinometer tube embedded in the internal portion of the pile. The buried depth of the inclinometer tube is equal to that of the retaining structure. It was fixed on the reinforcing cage and placed in the groove together and buried in the concrete. The axial force of the concrete support was calculated from the measured data of the steel bar stress meter embedded in the support section, assuming that the steel strain at the same section was equal to the concrete strain. Ground surface settlement is obtained by setting surface piles and observing with a leveling instrument. The ground settlement monitoring lines in different directions include 4 measuring points with a distance of $4 \mathrm{~m}$. The accuracy of each instrument is shown in Table 4.

3.2. Measured Results of the Lateral Wall Displacement. In this study, the representative diagonal positions $\mathrm{H} 12$ and H35 were selected at the intersection, and the actual displacement curves of the wall during the whole construction process are drawn, as shown in Figure 6. During the idealized excavation process, struts were installed during the initial stage of the excavation to reduce the cantilever rotation of the wall. However, due to the excavation sequence and site conditions, the struts needed to be installed layer by layer. The excavation process began from the cantilever state of the wall, and the support state transitions began from a single support to multiple supports. The first strut of the site was installed with a preexcavation groove. This was done, so there was no cantilever rotation of the wall during the initial stage of the excavation, which would have been in the form of a bulge.

From the measured results in Figure 6, it can be concluded that, during the excavation process, due to the lateral unloading, the outer retaining wall was laterally moved into the center of the excavation. In addition, the bulging of the external wall increased with the excavation depth, and the maximum displacement position $\left(H_{m}\right)$ moved down with excavation depth. The wall on the north side had a large displacement at the $\mathrm{H} 35$ measuring point of approximately $18 \mathrm{~mm}$, and the maximum position appeared at a depth of $12 \mathrm{~m}$ below ground surface. During the entire excavation process, the horizontal displacement at the top of the wall at the H35 measuring point was nearly zero, mainly because the pile at this position was constrained by the concrete support in two directions. In addition, it can be seen from the monitoring results that the displacement at the toe of the 
TABLE 2: Materials and dimensions for each layer of support in all directions.

\begin{tabular}{|c|c|c|c|}
\hline Section & Prop level included & Material & Cross section \\
\hline \multirow[t]{2}{*}{ A-A } & Prop 1-3 & Reinforced concrete & $\begin{array}{l}\text { Horizontal props: } 0.8 \mathrm{~m} \text { wide } \times 1.0 \mathrm{~m} \text { high } \\
\text { Diagonal props: } 0.8 \mathrm{~m} \text { wide } \times 0.8 \mathrm{~m} \text { high }\end{array}$ \\
\hline & Prop 4-5 & Steel & Intensive props: $609 \mathrm{~mm}$ external diameter and $16 \mathrm{~mm}$ thick \\
\hline \multirow[t]{2}{*}{$B-B$} & Prop 1-3 & Reinforced concrete & $\begin{array}{l}\text { Main props: } 0.8 \mathrm{~m} \text { wide } \times 0.8 \mathrm{~m} \text { high } \\
\text { Connecting props: } 0.6 \mathrm{~m} \text { wide } \times 0.6 \mathrm{~m} \text { high }\end{array}$ \\
\hline & Prop 4 & Reinforced concrete & $0.8 \mathrm{~m}$ wide $\times 1.0 \mathrm{~m}$ high \\
\hline The other two directions & Prop 1-3 & Reinforced concrete & $\begin{array}{l}\text { Main props: } 0.8 \mathrm{~m} \text { wide } \times 0.8 \mathrm{~m} \text { high } \\
\text { Connecting props: } 0.6 \mathrm{~m} \text { wide } \times 0.6 \mathrm{~m} \text { high }\end{array}$ \\
\hline
\end{tabular}

TABLe 3: Construction sequence for the finite element analysis.

\begin{tabular}{|c|c|c|}
\hline Stage & Construction details & Day \\
\hline \multicolumn{3}{|c|}{ Before excavation } \\
\hline I & Construction of diaphragm wall & $2018 / 08 / 01$ \\
\hline \multicolumn{3}{|c|}{ External excavation } \\
\hline II-1 & Excavation to $1.9 \mathrm{~m}$ below ground surface & \\
\hline II-2 & Installing prop 1 at $1.4 \mathrm{~m}$ below ground surface & $10 / 23$ \\
\hline II-3 & Excavation on the east-west sides to $8.1 \mathrm{~m}$ below ground surface & \\
\hline II-4 & Install prop 2 on the east-west side at $7.6 \mathrm{~m}$ below ground surface & \\
\hline II-5 & Excavation on the east-west sides to $13.7 \mathrm{~m}$ below ground surface & \\
\hline II-6 & Installing prop 3 on the east-west side at $13.2 \mathrm{~m}$ below ground surface & \\
\hline II-7 & Excavation on the east-west sides to $16.9 \mathrm{~m}$ below ground surface (reaching the bottom of outer excavation) & \\
\hline III-1 & Excavation at the intersection to $8.1 \mathrm{~m}$ below ground surface & \\
\hline III-2 & Installing the prop 2 at the intersection at $7.6 \mathrm{~m}$ below ground surface & $12 / 10$ \\
\hline III-3 & Excavation at the intersection to $13.7 \mathrm{~m}$ below ground surface & \\
\hline III-4 & Installing the prop 3 at the intersection at $13.2 \mathrm{~m}$ below ground surface & $2019 / 01 / 20$ \\
\hline III-5 & Excavation at the intersection to $16.9 \mathrm{~m}$ below ground surface (reaching the bottom of outer excavation) & $02 / 05$ \\
\hline \multicolumn{3}{|c|}{ 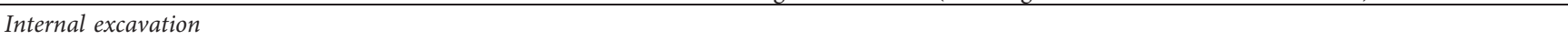 } \\
\hline IV-1 & Excavation at the intersection to $18.2 \mathrm{~m}$ below ground surface & \\
\hline IV-2 & Installing the prop 4 at the intersection at $17.7 \mathrm{~m}$ below ground surface & $02 / 15$ \\
\hline IV -3 & Excavation at the intersection to $22.4 \mathrm{~m}$ below ground surface & \\
\hline IV -4 & Installing the prop 5 at the intersection at $21.9 \mathrm{~m}$ below ground surface & $03 / 13$ \\
\hline IV-5 & Excavation at the intersection to $25.8 \mathrm{~m}$ below ground surface (reaching the bottom of inner excavation) & $04 / 10$ \\
\hline
\end{tabular}

pile was small, basically within $2 \mathrm{~mm}$, indicating that the pile end was approximately fixed during the PIP excavation, and the pile has sufficient embedding depth.

The wall displacement of the two measuring points increased slightly during the excavation of the inner pit. The maximum lateral wall displacement $\delta_{h-m}$ of the H12 and H35 measuring points increased by $18.5 \%$ and $15 \%$, respectively, when the inner excavation was completed. This increased percentage was based on the completion of the outer excavation. In addition, $H_{m}$ remained basically unchanged during the inner excavation. It shows that the external excavation plays a leading role in the deformation of the outer pit retaining wall, and the inner excavation had little effect on the deformation of the outer wall. This is because the excavation position of the inner pit in this project is in the center area of the outer pit; the piles of the inner pit strengthen the soil at the bottom of the pit on the one hand and hinder the further development of the shear failure surface in the soil caused by the excavation of the outer pit on the other hand.

3.3. Measured Results of the Ground Surface Settlement. According to the symmetry of the excavation plane, three lines S11, S12, and S21 were selected in this study. S11 was used to monitor the ground settlement behind the wall at the deepest excavation depth. S11-1 means the measuring point with a distance of $4 \mathrm{~m}$ behind the wall in No. 11 measuring point, which was the closest to the wall, and S114 was the farthest from the wall with a distance of $16 \mathrm{~m}$. The measuring points S12 and S21 were located at the corners of the southeast and northeast sides, respectively. Figure 7 shows the on-site monitoring results of the ground settlement during the entire construction of the three measuring points.

It can be drawn from Figure 7 that surface settlement mainly occurs during the outer excavation. The maximum settlement of the S11, S12, and S21 survey lines at the completion of the outer excavation accounted for $65 \%, 72 \%$, and $69 \%$ of the maximum settlement at the completion of the entire construction process, respectively. During the excavation of the inner pit, the settlement value of most of the measuring points tended to be stable, but the S21-3 further increased. The main reason was that the measuring point was affected by the simultaneous excavation of the standard section on the east side of line 4 . The simultaneous excavation of two adjacent construction sections should be avoided, and the construction method of skip excavation should be adopted as much as possible.

In the final stage of the excavation of the inner pit (IV5 ), the surface settlement of all the measuring points had 


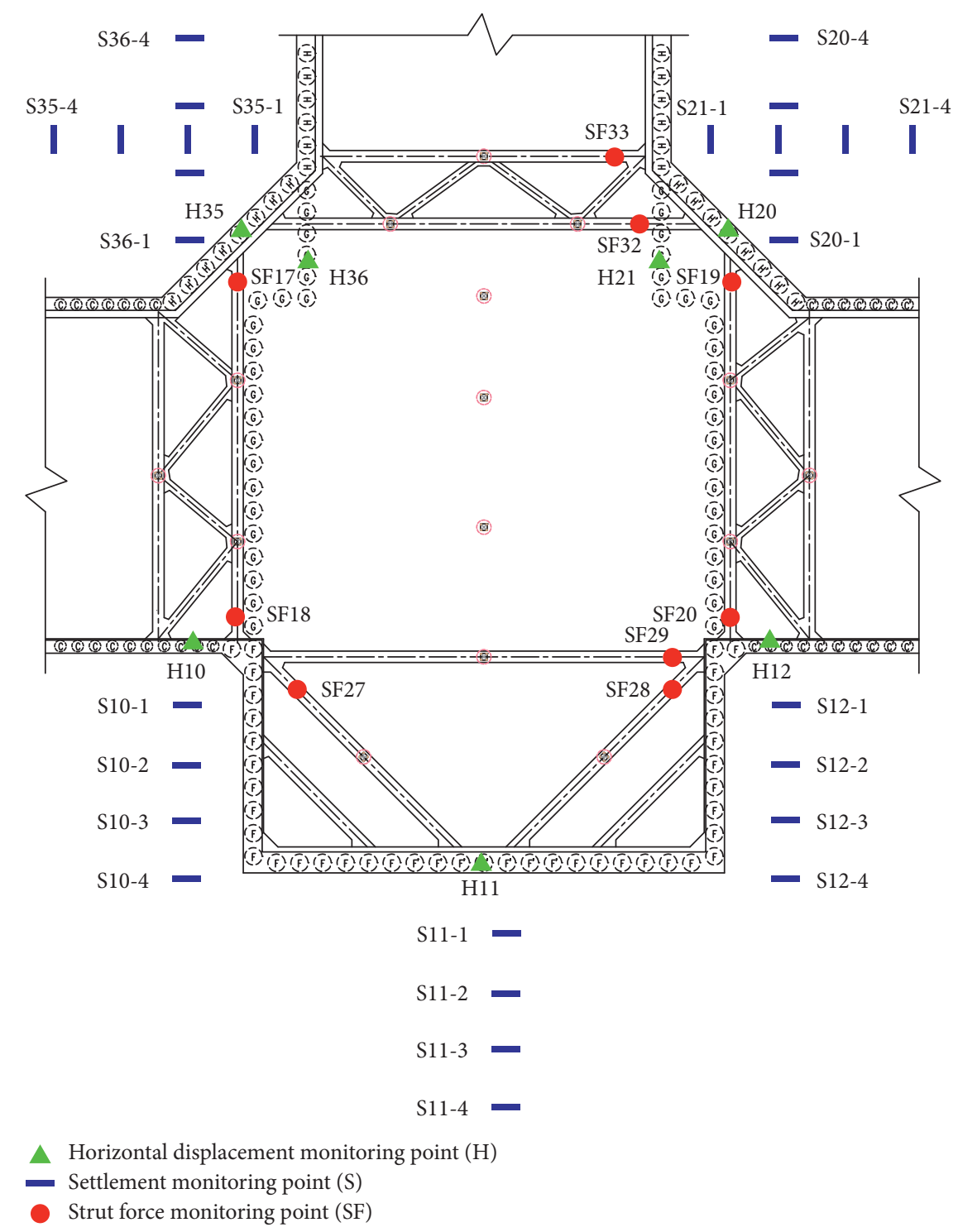

FigURE 5: Layout of monitoring points.

TABle 4: The accuracy of each instrument.

\begin{tabular}{lccc}
\hline Instrument & Inclinometer tube & Rebar stress gauge & Leveling instrument (mm) \\
\hline Accuracy & $0.2 \mathrm{~mm} / \mathrm{m}$ & $0.4 \%$ F.S. & 0.1 \\
\hline
\end{tabular}

F.S.: full name is "full scale," which means full scale output value.

further increased, because when the design elevation of the inner pit bottom was reached, the construction speed slows down, so that the time for the soil at the pit bottom to be exposed to the air increases. Due to the stress relaxation of the soil, the earth pressure in the active area behind the wall continues to increase with time, and the earth pressure in the passive area decreases continuously. The safety of the foundation pit gradually decreases, and the further lateral wall deformation causes the surface settlement behind the wall to increase. After excavation at the design elevation of the pit bottom, plain concrete cushions should be poured in a timely manner at certain intervals to reduce the exposure time and disturbance of the soil.

Figure 8 shows the surface settlement profile of the different points at the completion of construction. It can be seen from the figure that the position of the maximum settlement value $\left(V_{m}\right)$ of the surface behind the wall is different depending on the position of the measuring point. For the S11 measuring point with the largest excavation depth, the maximum settlement $\delta_{v-m}=11.89 \mathrm{~mm} . V_{m}$ is located at S11-2, and $V_{m}$ is the closest to the wall of all the selected three measuring points. The S12 measuring point was affected by the excavation in the north and west 


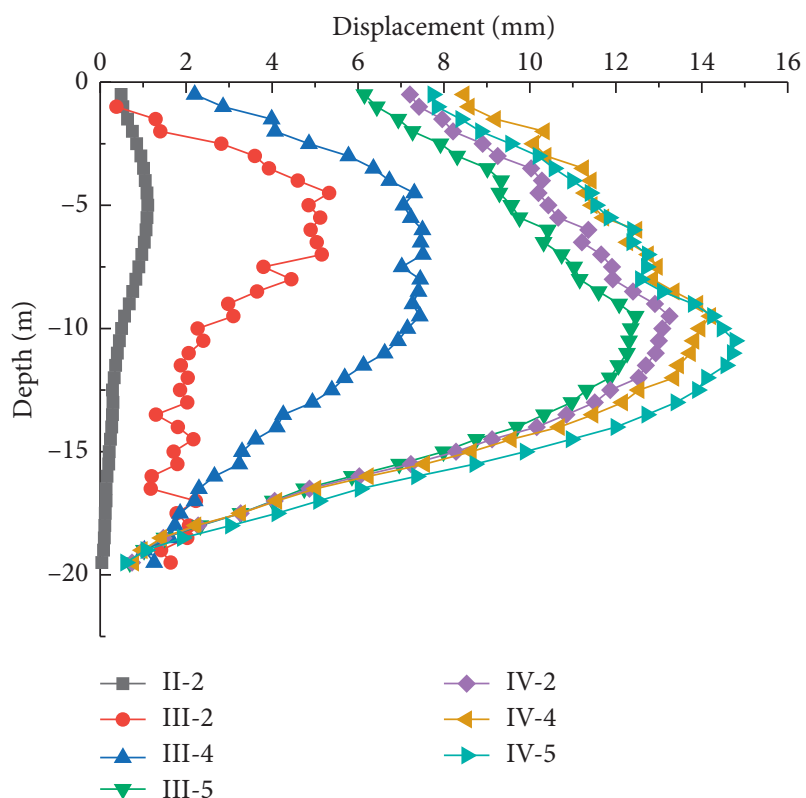

(a)

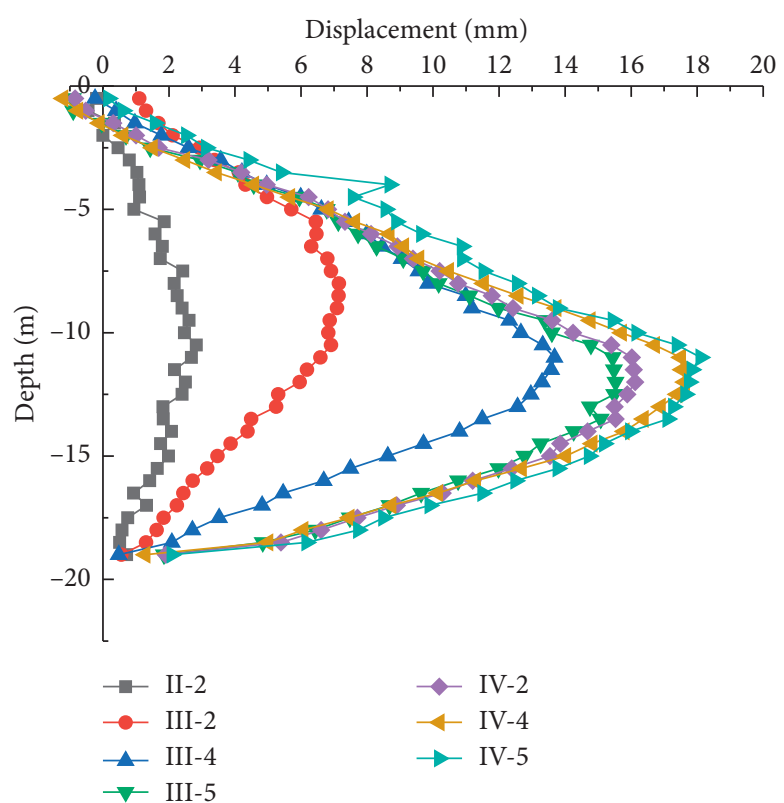

(b)

Figure 6: Monitoring results of the lateral wall displacement at (a) H12 and (b) H35 during the PIP excavation.

directions, and $\delta_{v-m}=13.84 \mathrm{~mm}$ and $V_{m}$ was located in S124. This demonstrates that the existence of the corner effect affected the deformation characteristics of the foundation pit excavation so that $\delta_{v-m}$ increased and $V_{m}$ moved away from the wall. The surface settlement value of S21 was the largest at $15.9 \mathrm{~mm} . V_{m}$ was between S11 and S12. This phenomenon occurred because there was a certain angle in space between the strut force and the earth pressure on the wall. Part of the strut force was used to balance the shearing force of the joint between the strut and the retaining wall, so that the support function of the struts was reduced.

3.4. Measured Results of the Strut Forces. The west side data points SF17 and SF18 and the south side data points SF27, SF28, and SF29 were selected in the two orthogonal directions of the intersection. The monitoring results of the strut axial force during the PIP excavation are shown in Figure 9. The last digit of the monitoring point indicates the vertical brace position; for example, SF17-1 indicates the first brace of the SF17 measurement point.

For the two measuring points of the outer excavation, SF17 and SF18, the first strut wire was damaged during construction, and the second and third strut forces had an increasing trend throughout the construction process. The maximum strut force of the SF17 and SF18 data points was $2919 \mathrm{kN}$, both of which appeared in the second portions of the SF17 and SF18 data points, the SF17-2 and SF18-2 supports. For the inner excavation, in SF27, SF28, and SF29, the axial force of the first two supports was relatively gentle, while the axial force of the third support increased rapidly, especially during the inner excavation stage when the SF29-3 support axial force reached $3699 \mathrm{kN}$. Combined with the lateral displacement of the wall, it can be concluded that, during the excavation, the maximum lateral deformation position gradually moved down with an increase in the excavation depth, and the maximum displacement increased continuously. Under the coordinated action of structure and soil deformation, an increase in the excavation depth had more significant influence on the axial force of the bottom struts.

\section{Details of the Numerical Simulation}

Due to the limited measured data, the deformation characteristics of the entire excavation process could not be fully shown. Hence, the three-dimensional model of the finite element was used to further study the deformation laws at different positions in the deep excavation, as shown in Figure 10. Due to the low water content of the formation and the low groundwater level, the seepage effect was ignored in the simulation. By considering the calculation time and calculation accuracy, the mesh size of the excavation area was determined to be approximately $1.5 \mathrm{~m}$, and the model boundary was a coarse grid with a size of $5 \mathrm{~m}$. Because the focus of this study was on the intersection, the model reduced the number of grids by shortening the standard section distance for an excavation. Figure 10(a) shows a finite element model of a three-dimensional excavation. The overall model consists of 109,363 nodes and 220,964 elements. The soil was modeled using solid elements, and the support was modeled using node-coupled beam elements. The model considered the influence of the step method excavation on the deformation of the support system and excavated the soil on the east-west sides and the intersection position. Additionally, the soil interface at the intersection was in the form of three gradings (Figure 10(b)). The stability of the soil under self-weight 


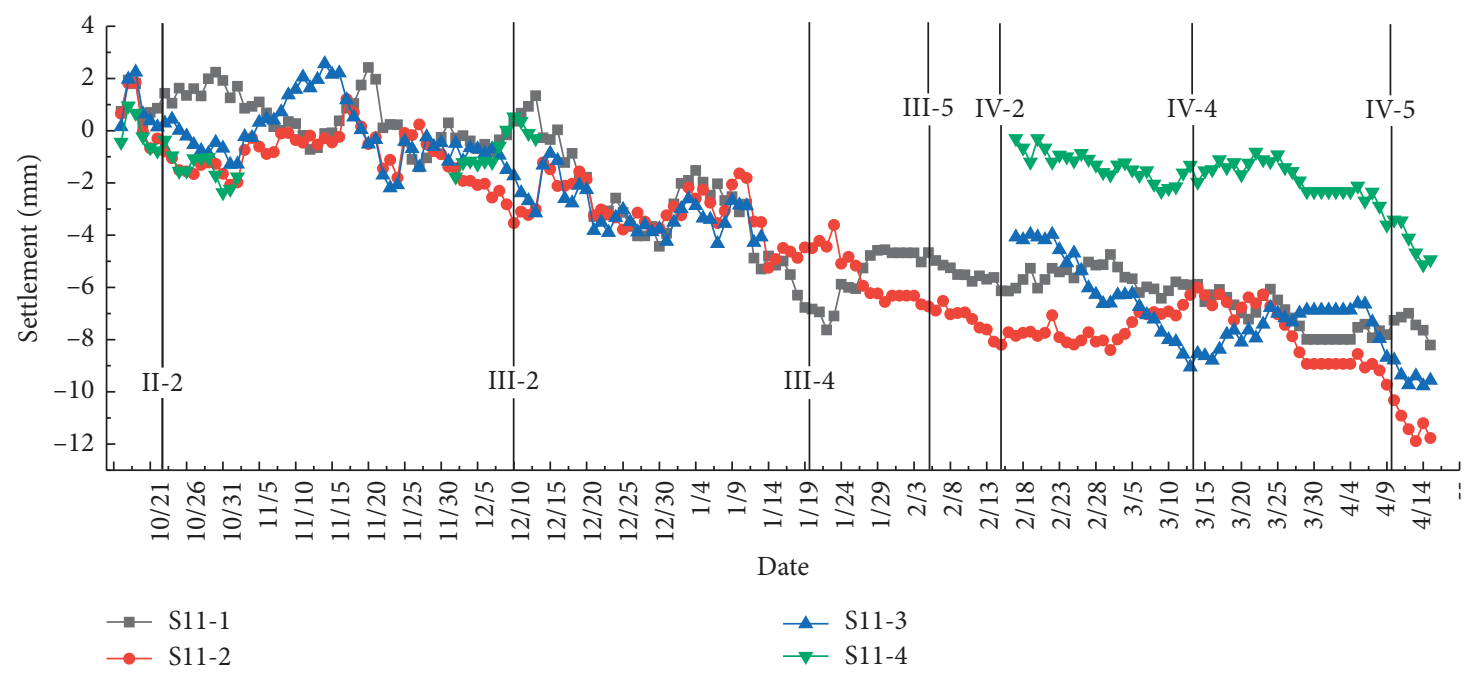

(a)

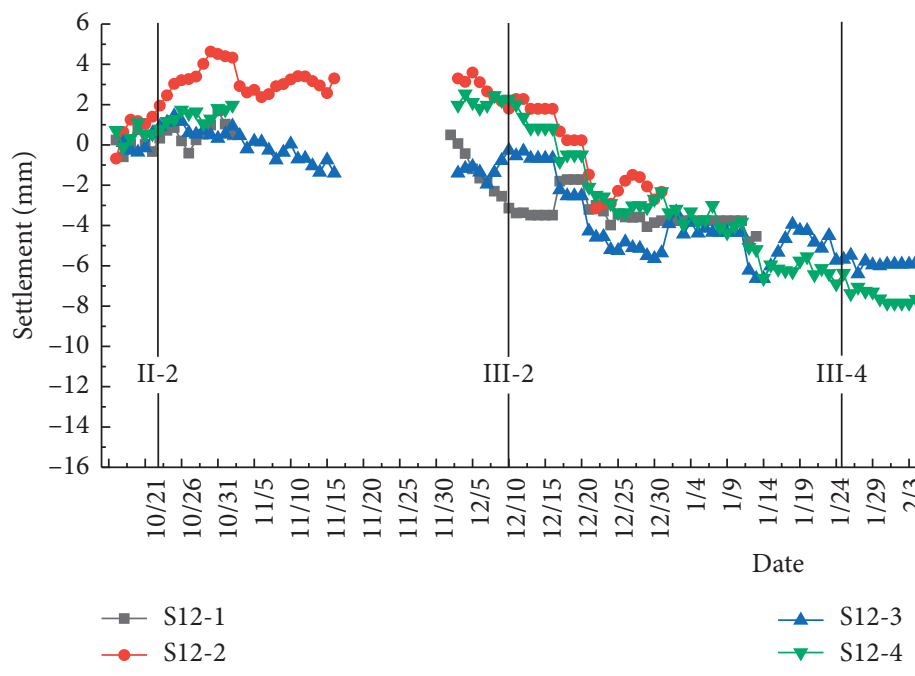

(b)

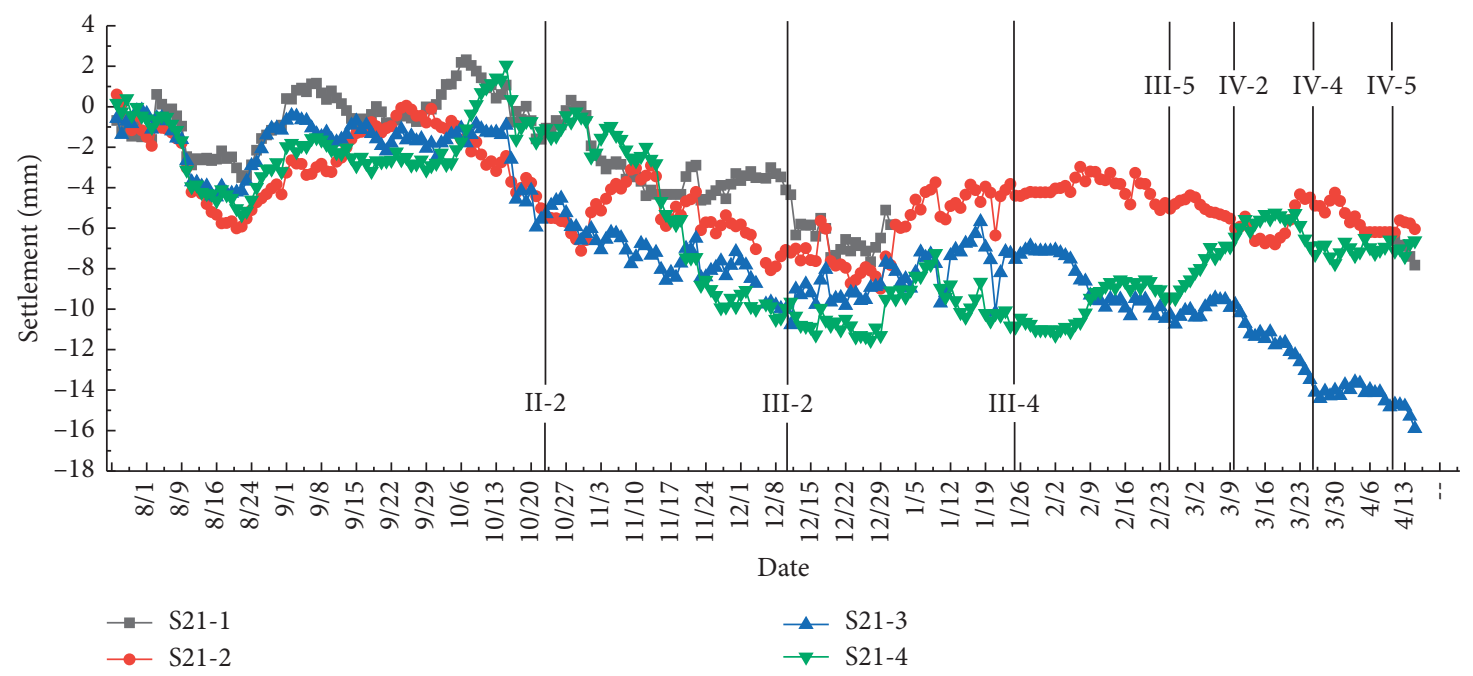

(c)

FIGURE 7: Monitoring results of the ground settlement at (a) S11, (b) S12, and (c) S21 during the PIP excavation. 


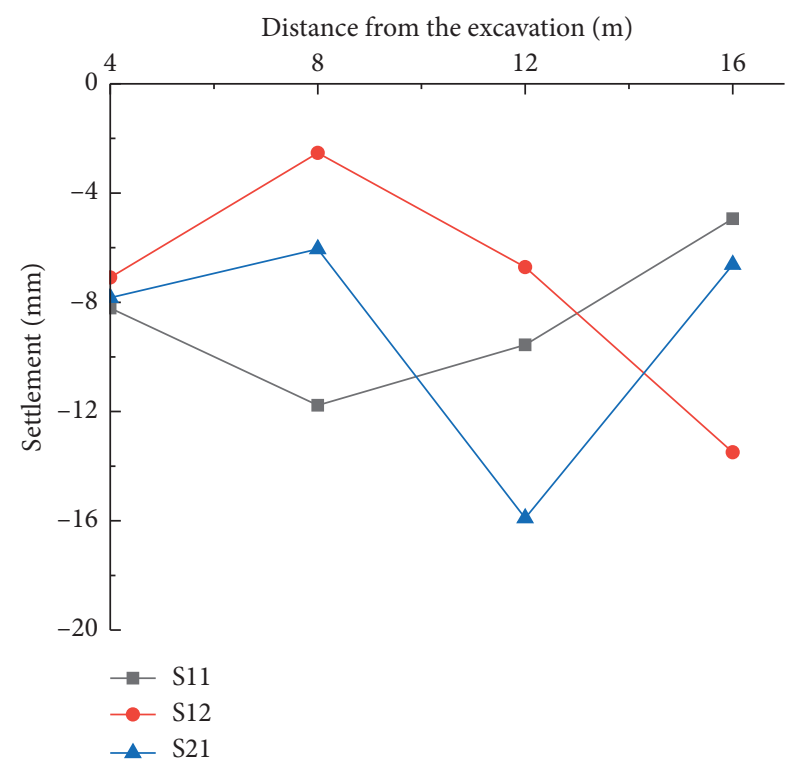

FIGURE 8: Settlement profile of S11, S12, and S21 measuring points when the excavation was completed.

was ensured, but it was closer to the actual construction conditions.

Because the model could not simulate the retaining pile system in the actual project, the retaining pile was replaced with the diaphragm wall using the following equation that utilizes the principle of equal stiffness:

$$
\frac{1}{12}(D+t) h^{2}=\frac{1}{64} \pi D^{2},
$$

where $D$ is the pile diameter, $t$ is the spacing of the center of the pile, and $h$ is the converted wall thickness. The diaphragm wall was modeled using an 8-node quadrilateral plate element with six degrees of freedom per node. The parameters of the retaining pile and the thickness of the diaphragm wall after transformation are shown in Table 5. Figure 11 shows the distribution of the diaphragm wall after the equivalent of the retaining pile.

The numerical simulation assumes that the soil follows the hardened soil (HS) model, because the model can simulate the hardening phenomenon where the increment of stress gradually decreases with strain. Geotechnical strength is described by triaxial test stiffness, triaxial unloading stiffness, and reloading strength, so it is more accurate than Mohr-Coulomb constitutive model to simulate the increase of foundation stiffness with compression. In addition, the model has functions of expansion limit to suppress excessive volume expansion and tensile strength limit to suppress excessive tension.

The effective cohesion $\left(C^{\prime}\right)$, effective friction angle $\left(\varphi^{\prime}\right)$, lateral pressure coefficient $\left(K_{0}\right)$, and compression modulus $\left(E_{S}\right)$ are shown in Table 1. Take on-site samples and use the GDS multifunctional triaxial apparatus (Figure 12) to perform a triaxial consolidated draining shear test to test the reference secant modulus $\left(E_{50}^{\text {ref }}\right)$ of the soil. Through laboratory tests and relevant literature, the HS model parameters are summarized as follows. In combination with the suggested values given in the Plaxis material models manual [25], unloading and reloading Poisson's ratio $\left(\nu_{\text {ur }}\right)$ was generally taken to be 0.2 . The reference stress $\left(p^{\text {ref }}\right)$ was generally taken to be $100 \mathrm{kPa} . R_{f}$ is the ratio of the deviatoric stress value corresponding to the point where $15 \%$ of the axial strain and the progressive value of the deviatoric stress exist, and the recommended value of $R_{f}$ was 0.9. Brinkgreve and Broere [25] gave the proportional relationship between the reference secant modulus $\left(E_{50}^{\text {ref }}\right)$, the reference tangent modulus $\left(E_{\text {oed }}^{\text {ref }}\right)$, and the reference unloading reload modulus $\left(E_{\mathrm{ur}}^{\text {ref }}\right)$. Wang et al. [26] obtained the triaxial test stressstrain curves and consolidation test load-strain relationship curve of typical soil layers in Shanghai based on the triaxial consolidation drainage shear test, the triaxial consolidation drainage unloading-reloading test, and the standard consolidation test. The proportional relationship between these moduli is discussed based on the results of Brinkgreve's research. It can be expressed using the following equations:

$$
\begin{aligned}
& E_{50}^{\mathrm{ref}}=E_{\text {oed }}^{\mathrm{ref}}, \\
& E_{\text {ur }}^{\mathrm{ref}}=3 E_{50}^{\mathrm{ref}} .
\end{aligned}
$$

According to Janbu [27], the power exponent, $m$, for sand and silt associated with the modulus stress level, is generally 0.5 . For cohesive soils, $m$ ranges from 0.5 to 1 . According to Bolton [28], the dilatancy angle $(\psi)$ can be assumed to be $\left(\varphi^{\prime}-30^{\circ}\right)$ for sand. For cohesive soils, $\psi$ is generally taken to be 0 . The parameters of the HS model used in the numerical simulation are shown in Table 6.

\section{Numerical Results}

5.1. Lateral Wall Displacements. Figure 13 shows the results of the three-dimensional numerical analysis of the deformation of the lateral wall during different excavation stages. The displacement of the wall at the H11 monitoring point with the largest excavation section was the largest, and the maximum lateral wall displacement $\left(\delta_{h-m}\right)$ of the outer excavation and the inner excavation was $32.77 \mathrm{~mm}$ and $54.34 \mathrm{~mm}$, respectively, which were $0.19 \%$ and $0.32 \%$ of the excavation depth of the foundation pit, respectively. For the H12 monitoring point, when the excavation of the east-west soil was completed (stage II-7) $\delta_{h-m}=8 \mathrm{~mm}$, the maximum deformation position, $H_{m}$, of the lateral wall gradually moved downward with an increase in the excavation depth. This was consistent with the conclusions obtained from the measured data. When the outer excavation was completed (stage III-5), $\delta_{h-m}$ of the $\mathrm{H} 12$ monitoring point was $19.1 \mathrm{~mm}$, which is approximately $0.11 \% H_{e}$, less than $0.19 \% H_{e}$ of the H11 measuring point. This indicated that an increase in the width of the excavation section will cause the displacement of the lateral wall to increase.

With the construction of the inner excavation, $\delta_{h-m}$ and $H_{m}$ of each monitoring point increased, and $H_{m}$ was approximately equal to $H_{e}$, which is consistent with the conclusions obtained by Ng et al. [17] based on the monitoring data. $\delta_{h-m}$ at the completion of the inner excavation (stage IV-5) at the $\mathrm{H} 12$ and $\mathrm{H} 35$ points was increased by $12 \%$ 


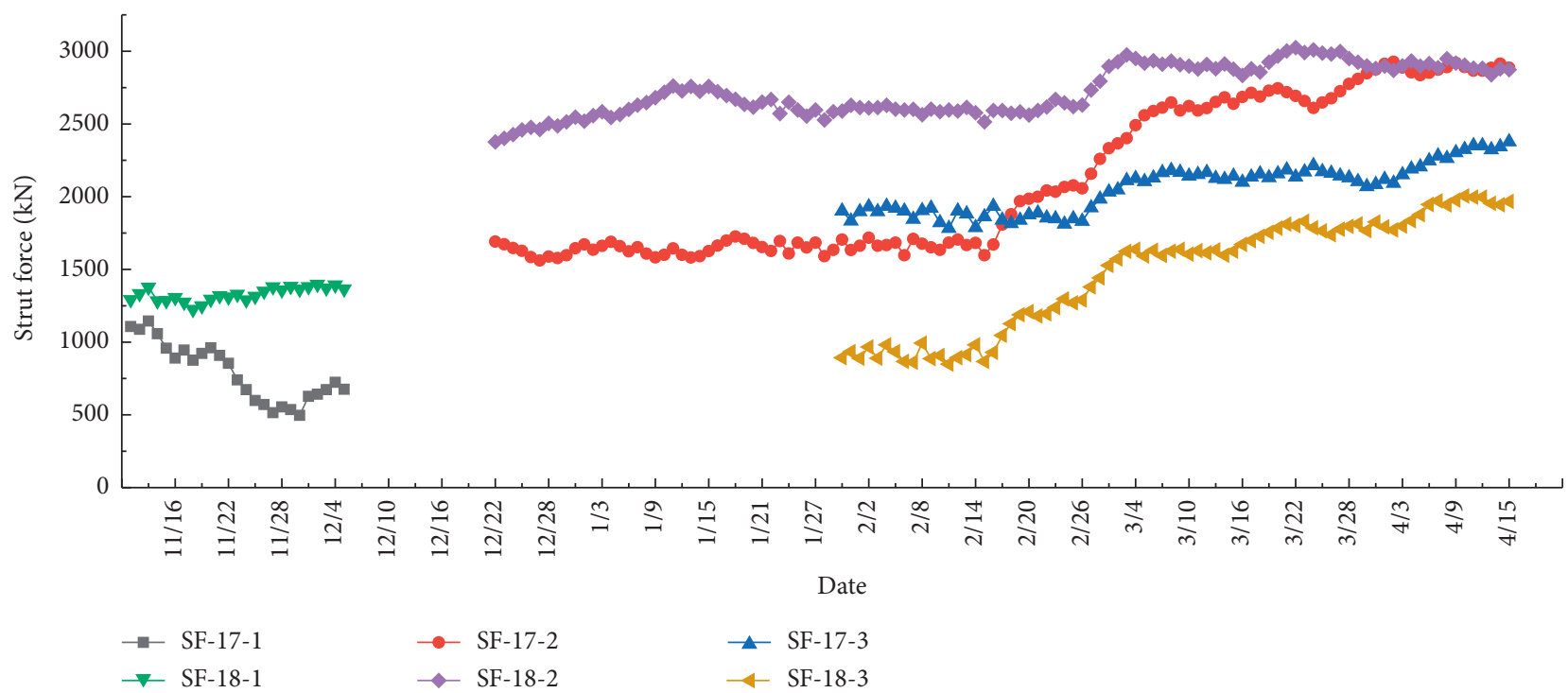

(a)

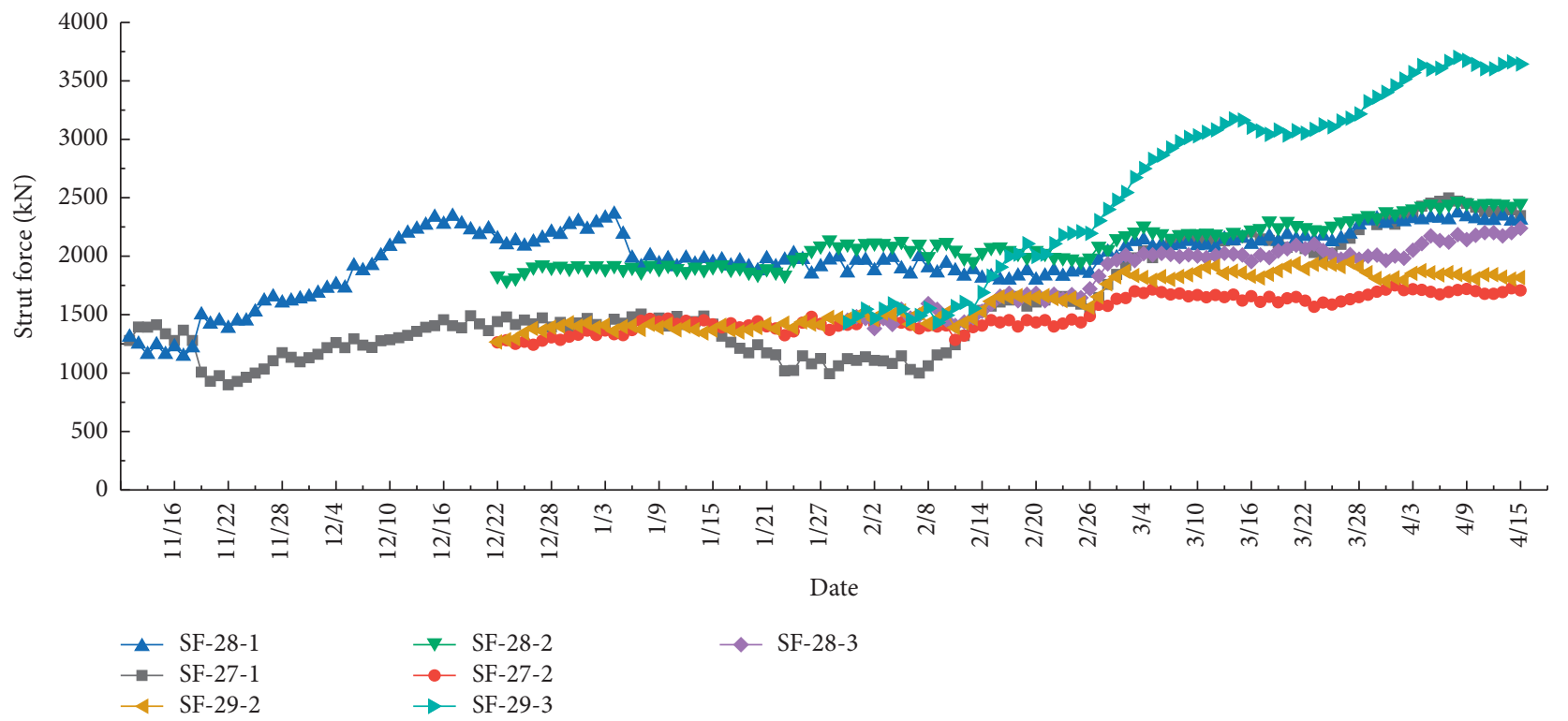

(b)

FIGURE 9: Monitoring results of the strut force at the west side (a) SF17 and SF18 and the south side (b) SF27, SF28, and SF29 during PIP excavation.

and $7 \%$, respectively, compared with the completion of the outer excavation (stage III-5). The significant increase in the displacement of the lateral wall of the H11 measuring point was primarily due to an increase in the excavation depth and a reduction in the strut stiffness. Therefore, the H11 measuring point did not reflect the influence of the inner excavation on the deformation of the external excavation supporting system. It can be seen from the strut distribution in Figure 4(a) that the fourth and fifth layer supports of the S11 were both steel struts, and these were reduced in compressive strength and rigidity compared with the first three concrete supports. Specification [29] stipulates that the maximum horizontal displacement of the supporting structure is $\delta_{h-m} \leq 0.15 \% H_{e}$ and $\delta_{h-m} \leq 30 \mathrm{~mm}$. The numerical calculation results showed that when the outer excavation was completed and the construction of the inner excavation was conducted, the displacement of the wall at monitoring point $\mathrm{H} 11$ was greater than the control value. Hence, a reinforcement plan should be developed in advance and on-site monitoring should be strengthened. Then, when the displacement approaches the control value, needed reinforcement measures can be taken in time.

Figure 13(d) shows the deformation curve of the H36 monitoring point at the inner pit retaining wall during different excavation stages. The excavation of the east-west soil did not affect the inner retaining structure, but the excavation of the soil at the upper part of the intersection caused a vertical unload that had a small effect on the 


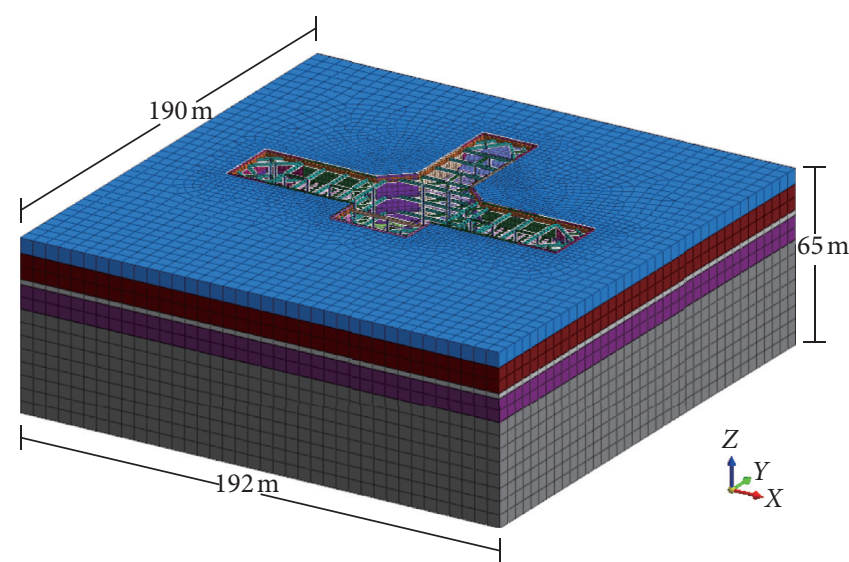

(a)

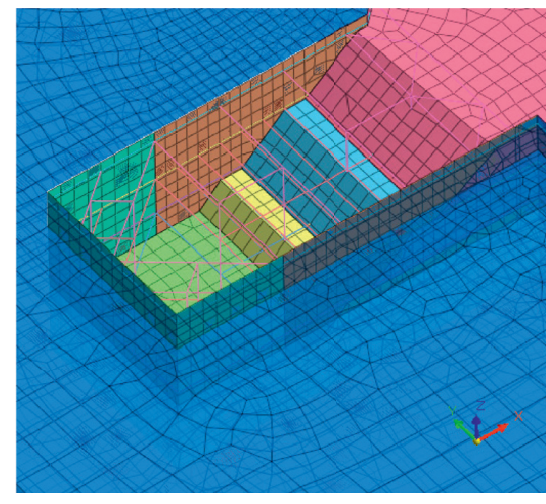

(b)

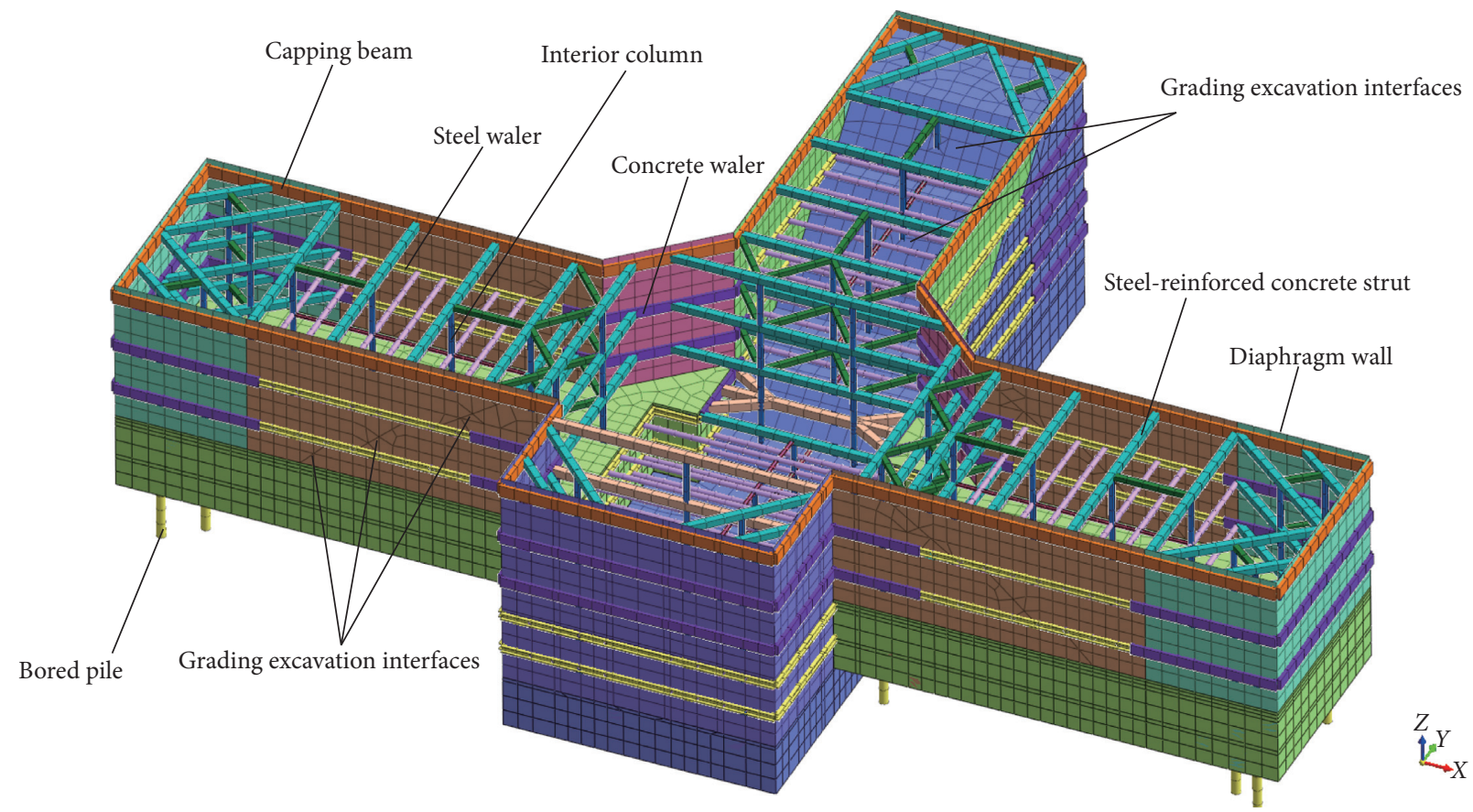

(c)

FIGURE 10: (a) Numerical model; (b) three gradings at the intersection; (c) cross position support distribution.

TABLE 5: The parameters of the pile and the wall.

\begin{tabular}{lcccc}
\hline Type of pile & Pile diameter $(\mathrm{mm})$ & Spacing of the center of the pile $(\mathrm{mm})$ & Converted wall thickness $(\mathrm{mm})$ & Type of wall \\
\hline A & 800 & 1000 & 623 & 603 \\
B & 800 & 1100 & 586 & $\mathrm{~A}^{\prime}$ \\
C & 800 & 1200 & 914 & $\mathrm{~B}^{\prime}$ \\
D & 1200 & 1600 & 905 & $\mathrm{C}^{\prime}$ \\
E & 1200 & 1650 & $\mathrm{D}^{\prime}$ \\
F & 1200 & 1500 & $\mathrm{E}^{\prime}$ \\
\hline
\end{tabular}

deformation of the inner excavation lateral wall. The installation of the 4th and 5th braces inhibited the development of a displacement of the wall at the inner excavation, and the maximum displacement of the lateral wall was close to the wall too. The deformation curve of the inner wall was different from the bulging of the outer wall, and it manifested more as tilting and deflection, but the maximum deformation was less than $10 \mathrm{~mm}$, which was far less than the control value, and meets the requirements of the specification.

Figure 14 shows the relationship between the maximum lateral deformation and the depth of excavation obtained 


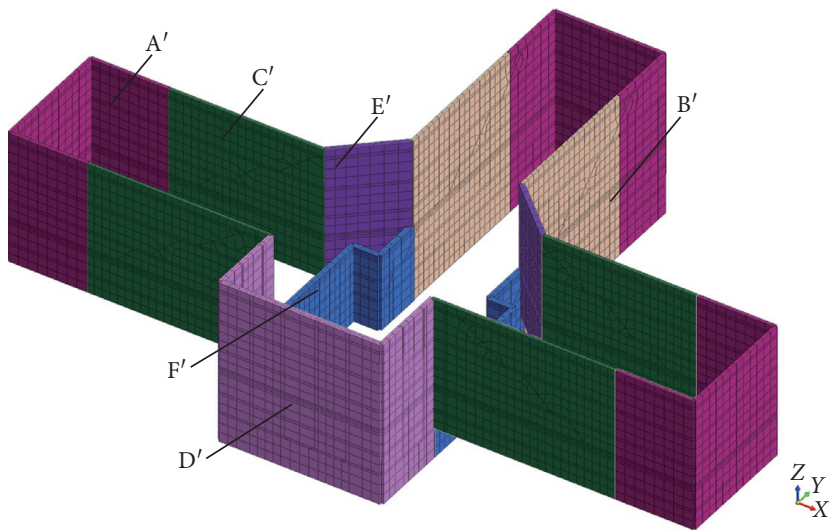

FIGURE 11: Distribution of the diaphragm wall.

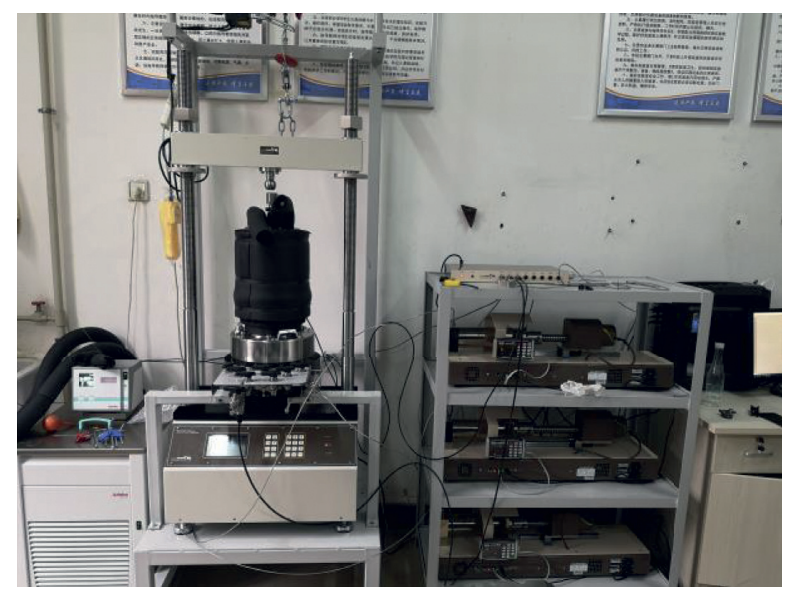

(a)

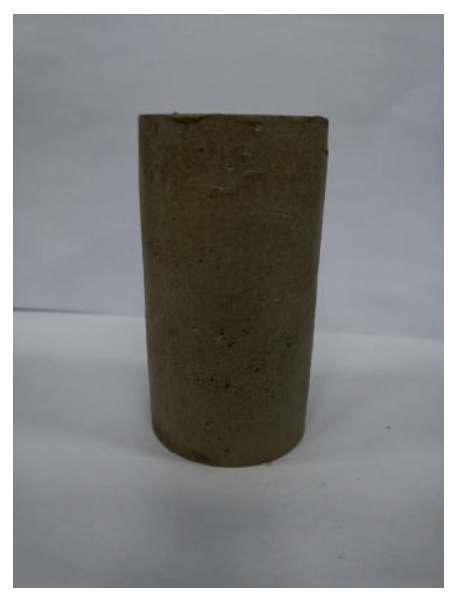

(b)

Figure 12: GDS equipment (a) and prepared specimens (b).

TABle 6: The parameters of the HS model.

\begin{tabular}{lcccccc}
\hline Parameter & Unit & Fill & Medium clay & Stiff clay & Strongly weathered sandy mudstone & Moderately weathered sandy mudstone \\
\hline$\gamma_{\text {unsat }}$ & $\mathrm{kN} / \mathrm{m}^{3}$ & 18.8 & 19.5 & 19.9 & 21.3 & 21.7 \\
$\gamma_{\text {sat }}$ & $\mathrm{kN} / \mathrm{m}^{3}$ & 18.8 & 19.5 & 19.9 & 21.3 & 21.7 \\
$C^{\prime}$ & $\mathrm{kN} / \mathrm{m}^{2}$ & 10 & 55 & 36 & 45 & 50 \\
$\varphi^{\prime}$ & $\circ$ & 8 & 14 & 16 & 20 & 25 \\
$K_{0}$ & - & 0.65 & 0.39 & 0.38 & 0.32 & 0.30 \\
$\psi$ & $\circ$ & 0 & 0 & 0 & 0 & 0 \\
$E_{50}^{\text {ref }}$ & $\mathrm{kN} / \mathrm{m}^{2}$ & 8054 & 12,167 & 13,286 & 27,860 & 33,640 \\
$E_{\text {oed }}^{\text {ref }}$ & $\mathrm{kN} / \mathrm{m}^{2}$ & 8054 & 12,167 & 13,286 & 27,860 & 33,640 \\
$m$ & - & 0.8 & 0.8 & 0.8 & 0.5 & 0.5 \\
$E_{\text {ur }}^{\text {ref }}$ & $\mathrm{kN} / \mathrm{m}^{2}$ & 24,162 & 36,501 & 39858 & 0.2 & 100,920 \\
$\nu_{\text {ur }}$ & - & 0.2 & 0.2 & 0.2 & 100 & 0.2 \\
$p^{\text {ref }}$ & $\mathrm{kN} / \mathrm{m}^{2}$ & 100 & 100 & 100 & 0.9 & 100 \\
$R_{f}$ & - & 0.9 & 0.9 & 0.9 & 27,860 & 0.9 \\
$E_{S}$ & $\mathrm{kN} / \mathrm{m}^{2}$ & 8054 & 12,167 & 13,286 & 0.5 & 33,640 \\
$e_{0}$ & - & 0.8 & 0.7 & 0.6 & & 0.5
\end{tabular}

from simulation results and measurements. It also summarizes the measured results of the deep excavation by Wang et al. [11]. It can be seen from the figure that both simulation and measurement in this study are included in $\delta_{h-m}=(0.03 \%-0.12 \%) H_{e}$. In other cases, as the depth of excavation increased, $\delta_{h-m}$ grew faster and tended to $0.5 \% H_{e}$. However, the simulated and measured $\delta_{h-m}$ growth rate of this site during the inner excavation was close to 0 , indicating that the impact of the inner excavation on the diaphragm wall of the outer excavation was small. 


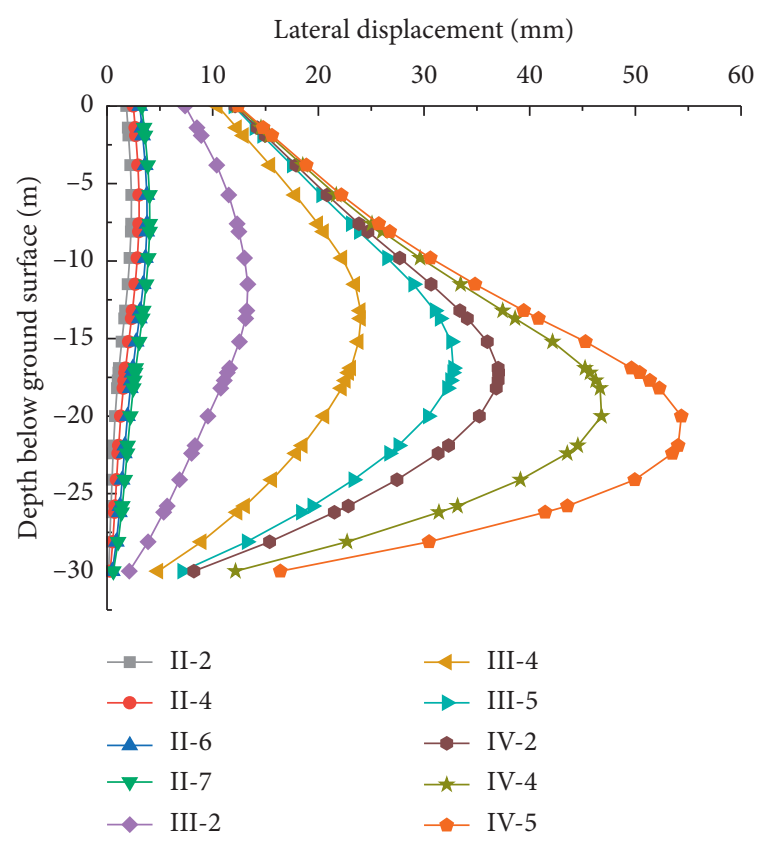

(a)

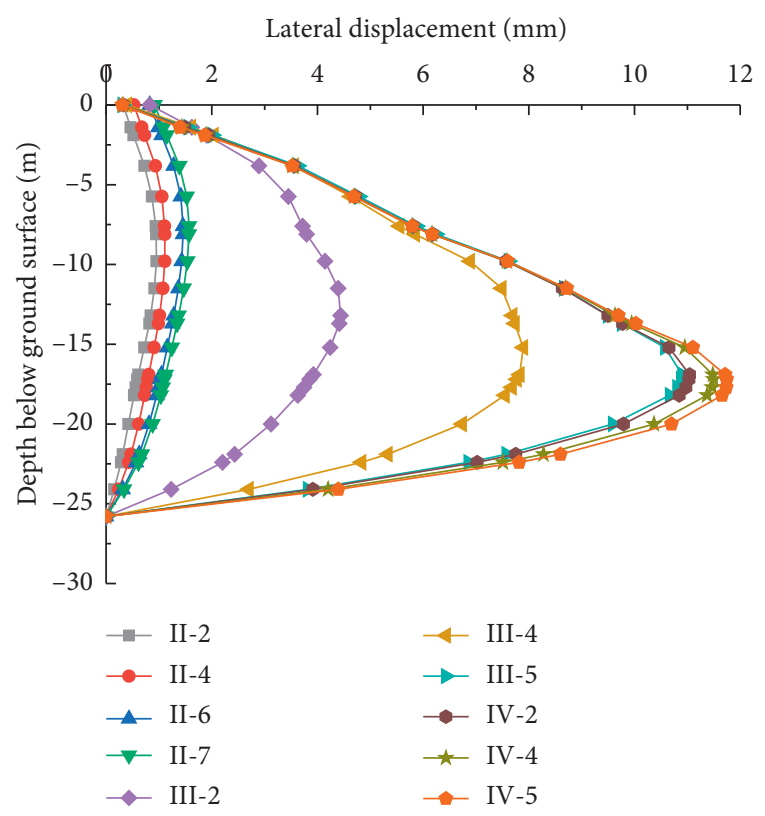

(c)

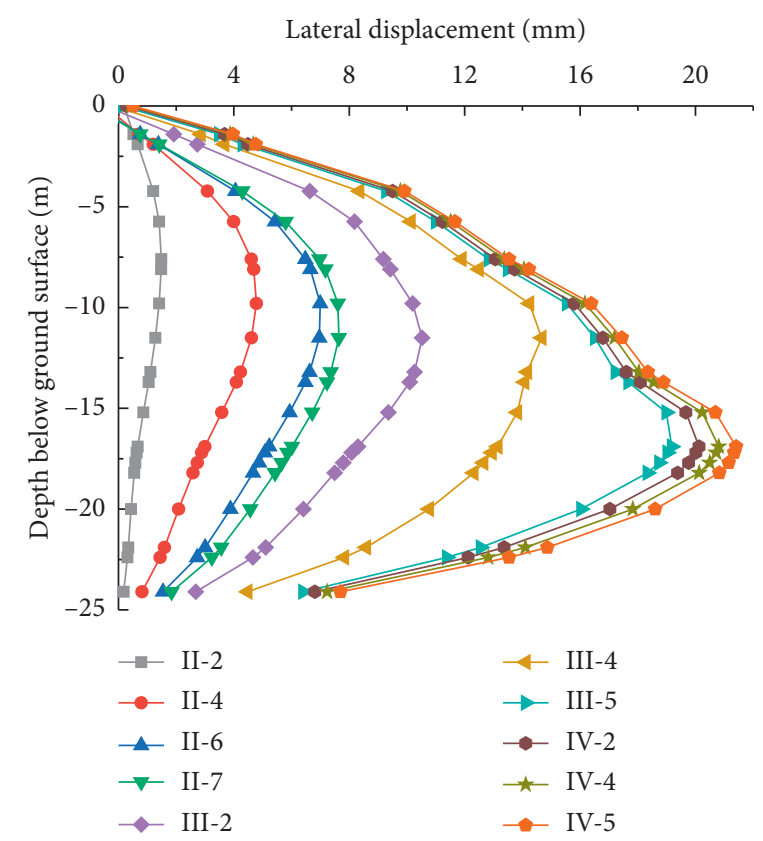

(b)

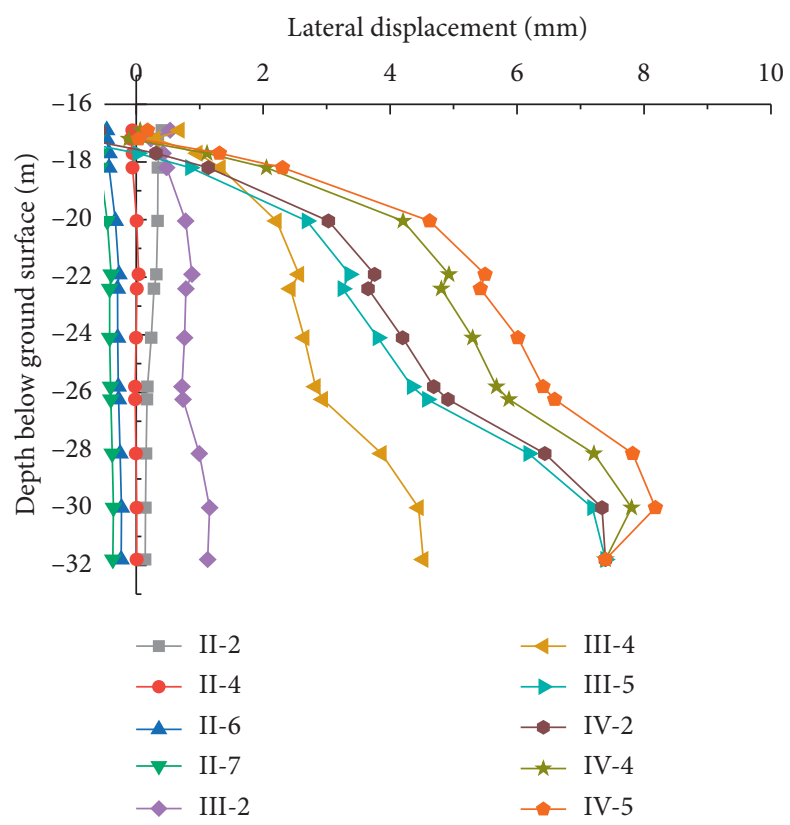

(d)

Figure 13: Numerical results of lateral wall displacements at H11 (a), H12 (b), H35 (c), and H36 (d).

Figure 15 shows the relationship between the maximum lateral deformation depth and the excavation depth obtained from the simulation results and measurements. It also summarizes the measured results of China [11]. The results show that, except for several data points during the initial stage, most of the data points in this study are below the line $H_{m}=H_{e}$, while the data from the Shanghai metro stations indicate that this occurs at a depth in the range of $H_{m}=H_{e}$ and $H_{m}=H_{e}+10$. The main reason for this difference was that the excavation in Shanghai uses prestressed props.
5.2. Ground Surface Settlement. There are generally two types of settlement profiles caused by excavation. One is the spandrel type, in which maximum surface settlement occurs very close to the wall when the excavation depth is small. The other is that as the depth of the excavation increases, the settlement profile becomes a concave type in which the maximum surface settlement occurs at a distance away from the supported wall.

Four surface settlement monitoring points corresponding to the lateral wall displacement monitoring points were selected to analyze the variations in surface settlement 


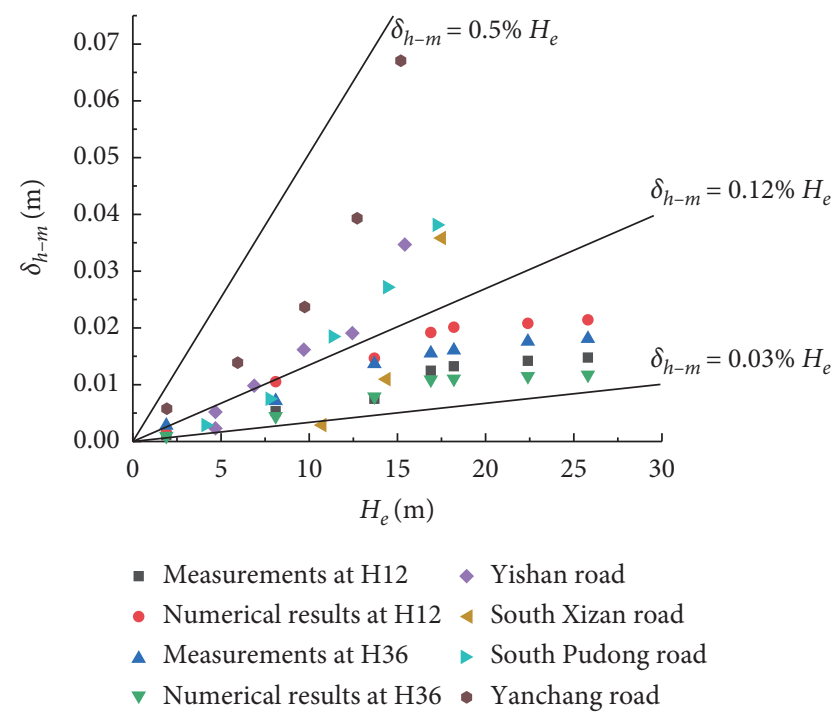

Figure 14: The relationship between the maximum lateral deformation $\left(\delta_{h-m}\right)$ and the excavation depth $\left(H_{e}\right)$ in this study and other cases.

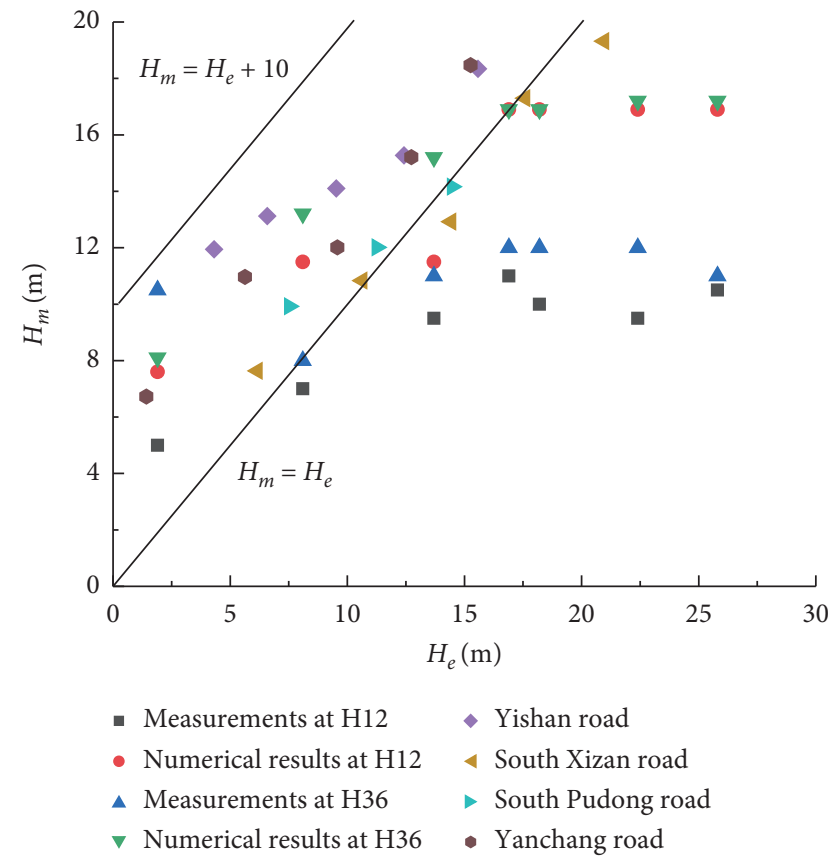

Figure 15: The relationship between the maximum lateral deformation depth $\left(H_{m}\right)$ and the excavation depth $\left(H_{e}\right)$ in this study and other cases.

during different excavation stages. Figure 16 shows the simulation results for the four surface settlement monitoring points. The results show that, with excavation, the maximum settlement positions $\left(V_{m}\right)$ of the different measuring points were not fixed but gradually moved away from the retaining wall, and the settlement profile changed from spandrel to concave. $V_{m}$ of S11 was the closest to the wall, followed by the S20 and S21 measuring points, and $V_{m}$ of S12 was the farthest from the wall. These results are consistent with the conclusions obtained from the measured data.
The settlement of S11 was the largest, and, since the depth of the excavation was the deepest $h=25.8 \mathrm{~m}$, the maximum settlement value $\left(\delta_{v-m}\right)$ was $11.2 \mathrm{~mm}$. The excavation of the east-west soil had little effect on the surface settlement after the intersection of the wall, and the surface settlement here was approximately $2 \mathrm{~mm}$. Excluding the $S 11$ measuring point, the internal excavation made $\delta_{v-m}$ of S12, S20, and S21 increase by 59\%, 17\%, and $15 \%$, respectively, compared with the completion of the external excavation. Because the S12 measuring point was close to the interface between the inner and outer excavations, the corner effect on the settlement of the ground surface behind the wall was significant. Hence, the settlement value fluctuated within $20 \mathrm{~m}$ behind the wall (Figure 16(b)), which was approximately 0.8 times the inner excavation depth. $V_{m}$ of $S 12$ increased compared with other measuring points and was approximately $30 \mathrm{~m}$ behind the wall.

As the depth of excavation increased, the range of the settlement values continued to expand. The numerical simulation results were affected by the calculation accuracy. The area where the surface settlement curve reached a stable value away from the wall was considered an unaffected area. It can be concluded from Figure 16 that the outer excavation played a leading role in the surface settlement range and the inner excavation further increased $\delta_{v-m}$, which had no effect on the surface settlement range. The influence range of the excavation obtained from the numerical simulation was larger than $3.0 H_{e}$, which was higher than that of Wang et al. [11] and Liu et al. [16], which were $2.0 H_{e}$ and $1.0 H_{e}$, respectively.

Peck [2] reported a diagram of the normalized maximum settlement versus the distance behind the wall and divided it into three regions. Zone I was sand and soft-tohard clay, zone II was very soft-to-soft clay, and zone III was very soft-to-soft clay to a great depth. The simulated and measured data in this study and the three areas summarized by Peck are shown in Figure 17. It can be seen from the figure that the predicted and measured values found in this study are very small, and the data points all fall within zone I.

5.3. Apparent Earth Pressure. To further analyze the stress level of the supporting axial force, the maximum load on each layer of strut was calculated using the apparent earth pressure diagram. In this study, the apparent earth pressure envelope during the excavation was estimated based on the maximum strut force of the on-site monitoring at the SF17 and SF18 measuring points of the outer excavation and the SF27, SF28, and SF29 of the inner excavation. Figure 18 refers to the tributary area load distribution procedure proposed by Peck to draw the idealized loading area of each layer in the project. The case of inner excavation $H_{e}=25.8 \mathrm{~m}$ was used as an example, where $h_{\mathrm{si}}$ represents the depth of the loading area of the corresponding strut.

The apparent earth pressure can be obtained according to the following equation, where each strut has an axial force, $\mathrm{P}$, strut horizontal spacing, $S_{H}$, and an idealized loading area: 


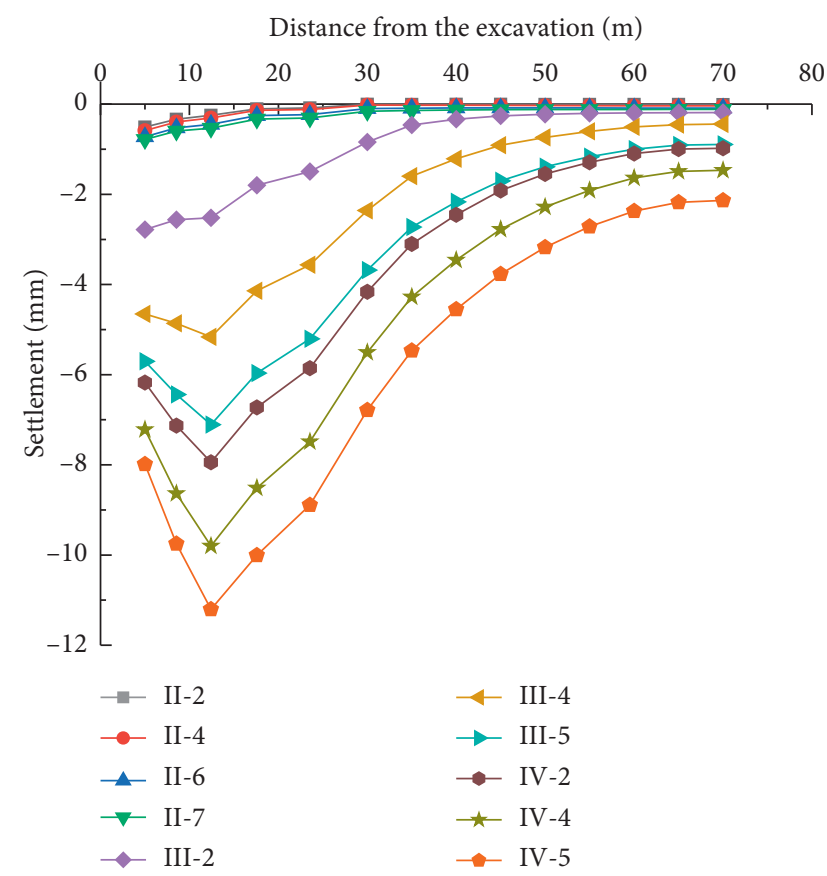

(a)

Distance from the excavation $(\mathrm{m})$

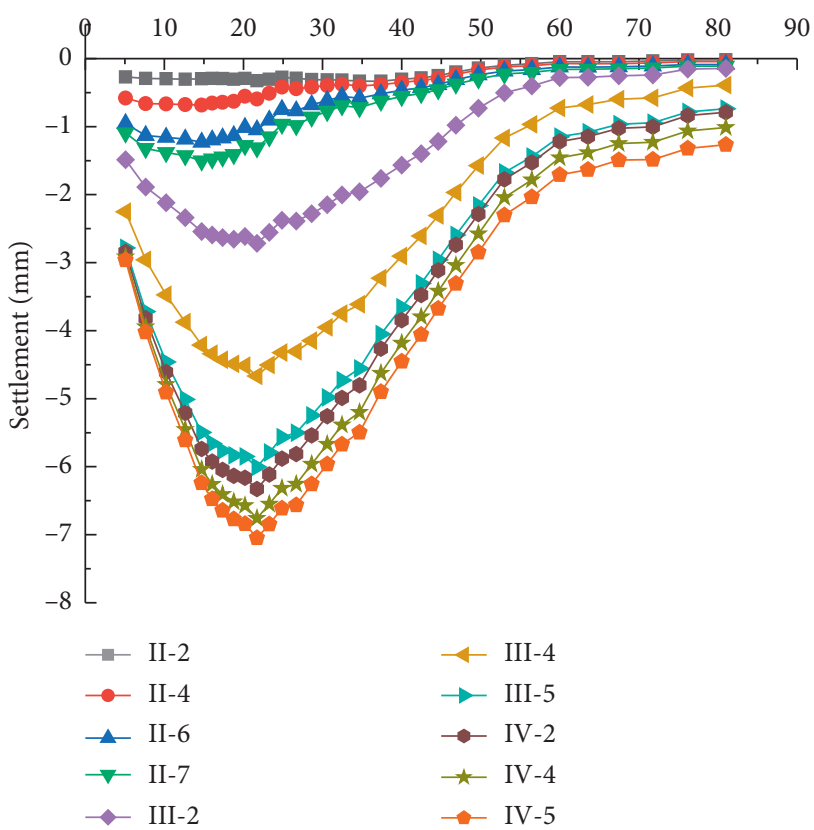

(c)

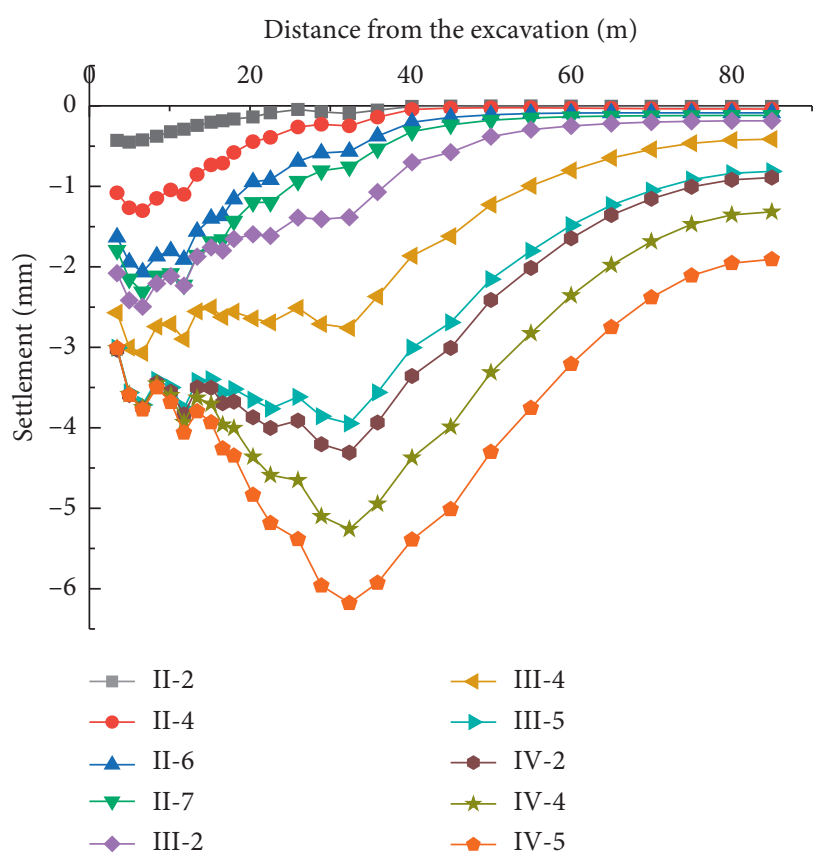

(b)

Distance from the excavation $(\mathrm{m})$

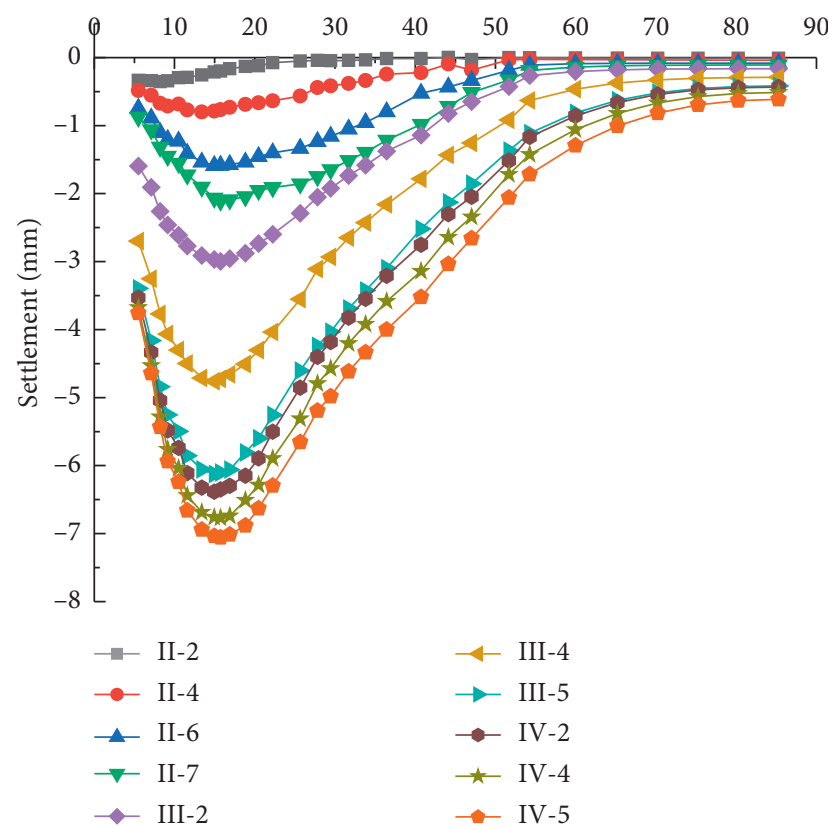

(d)

Figure 16: Numerical results of ground surface settlement at S11 (a), S12 (b), S20 (c), and H21 (d).

$$
\sigma_{h}=\frac{P}{S_{H} h_{s i}} .
$$

Thus, the relationship between the normalized apparent earth pressure $\left(\sigma_{h} / \gamma H_{e}\right)$ and the normalized depth $\left(z / H_{e}\right)$ was plotted, as shown in Figure 19. The limited measurement results in this study were compared with other cases in similar hard clays. Figure 19 includes the cases for Twine [19] and $\mathrm{Li}$ [30]. It can be seen from the figure that the apparent earth pressure is less than $0.5 \gamma H_{e}$, which is consistent with the characteristic line (red line) proposed by Twine and Roscoe. However, for most of the data in this study and in $\mathrm{Li}$ and Twine work, the apparent earth pressure value was less than $0.3 \gamma H_{e}$ (blue line), with the exception of four values in Twine that exceeded the predicted range and one value that was equal to the predicted value. For the PIP excavation project in this region, it is more reasonable to use $0.3 \gamma \mathrm{H}_{e}$ as the upper limit index of the strut axial force. When this value 


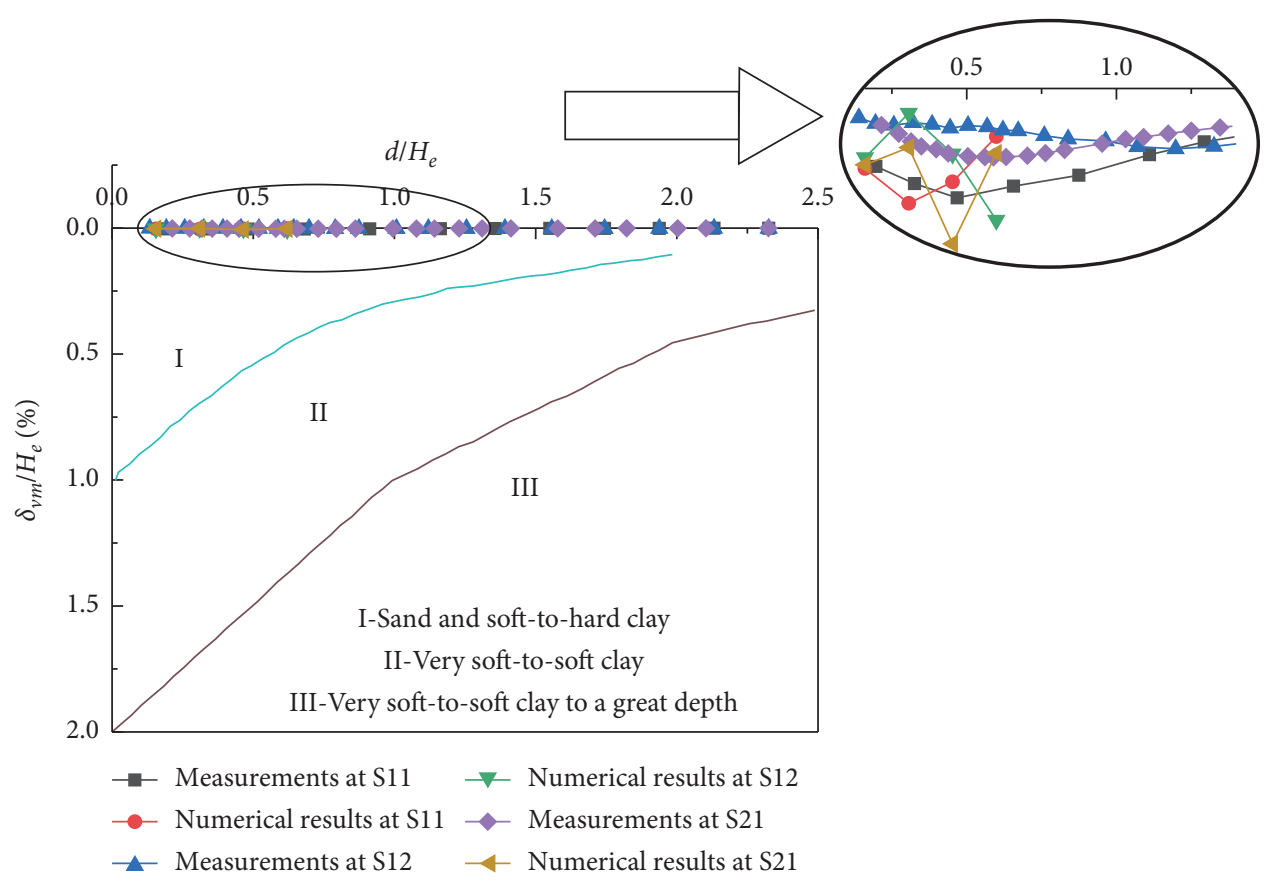

FIgURE 17: Numerical and measured ground surface settlement with distance behind the wall in Peck's diagram.

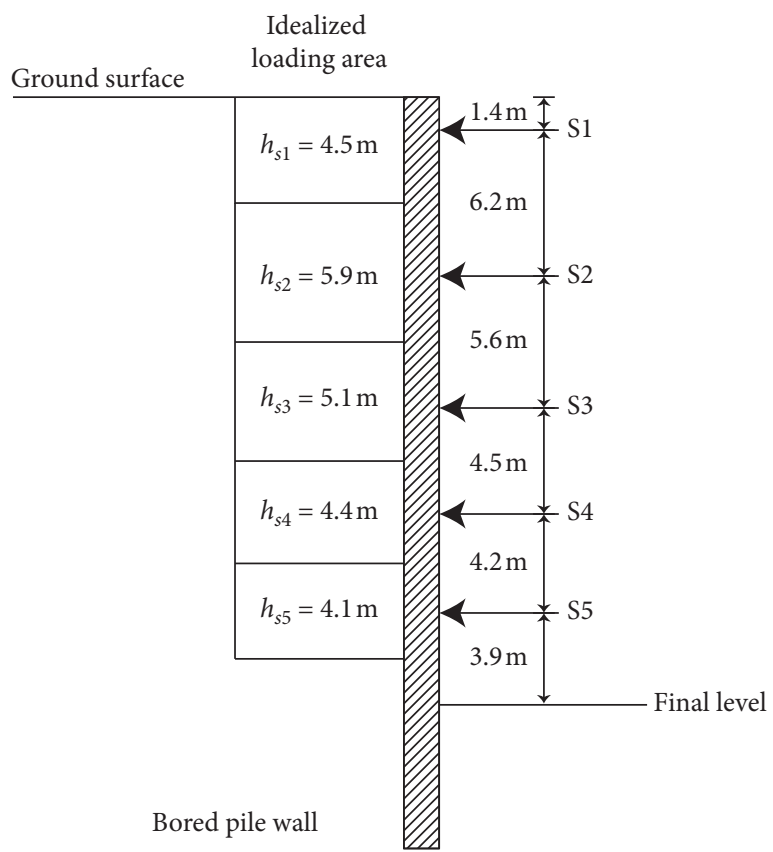

FIGURE 18: Cross section of idealized tributary loading areas of struts for $H_{e}=25.8 \mathrm{~m}$.

is exceeded, the engineers should be vigilant and review the measured data and consider taking reinforcement measures to guarantee construction safety.

\section{Discussion}

This study verifies the feasibility of the model in calculating the stress and deformation of stratum and structure during

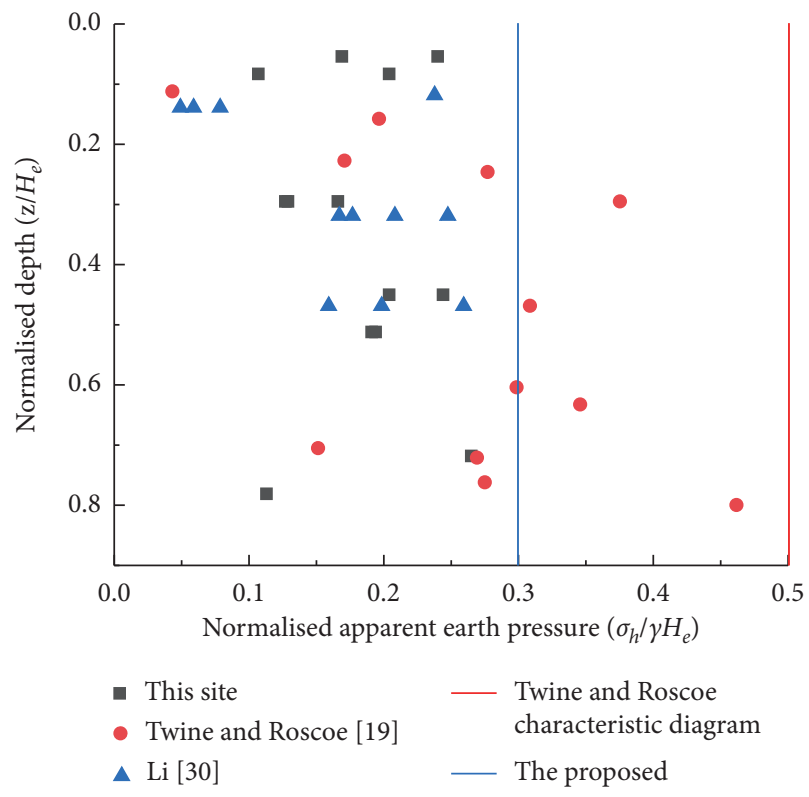

FIGURE 19: Normalized apparent earth pressure versus normalized depth for stiff walls in this region and other cases.

the PIP excavation through the comparison of the measurements and the numerical simulation results. It provides a guidance method for the construction of subsequent subway stations in this region. However, for the model and simulation method proposed in this study, there are still insufficient and required follow-up researches, summarized as follows:

(1) In determining the soil parameters, this study was limited by the available undisturbed soil samples, 
and a semiexperimental and semiempirical method had to be used. In the succession of the studies, it is necessary to obtain accurate soil parameters through more undisturbed soil tests. In addition, the influence of parameter changes on the calculation results also needs further study.

(2) In the foundation pit project, the steel brace has the advantages of light weight, low cost, and being conducive to construction compared with the concrete brace. Based on the calculation model in this study, one important future direction is to evaluate the feasibility of using steel braces with small spacing to replace concrete braces, which has an significant contribution to saving construction time and cost.

(3) In view of uncertain external factors, such as the structural stress redistribution caused by local support fractures, the accuracy of the prediction of the method in this study is of great significance for the safe construction of the PIP project.

\section{Conclusions}

In this study, the lateral displacement, surface settlement, and strut force variations of retaining pile were analyzed based on measured field data. Then, based on a triaxial consolidation draining shear test and previously reported research, the three-dimensional model parameters for simulating the deformation characteristics of a multibraced excavation were obtained. In addition, the deformation characteristics of different locations in the space were further studied. The measured results of the reported cases were also compared with the simulated and measured values from this study. The conclusions drawn from this research are as follows:

(1) The excavation of the outer pit caused the maximum lateral deformation of the wall to gradually move down and the maximum displacement to increase. Both the measurement and the simulation results indicated that the maximum lateral deformation of the pile caused by the outer excavation accounts for $80 \%-90 \%$ of the total deformation. Affected by the location of the inner excavation, the increase in the displacement of the outer pit pile caused by the inner excavation in this project was small, within $20 \%$. The simulated and measured maximum deformations in this study were included in $(0.03 \%-0.12 \%) \mathrm{H}_{\mathrm{e}}$, the growth rate during inner excavation tended to 0 , and the maximum lateral deformation depth was above the excavation surface, which indicated that, for this project, the inner excavation had little effect on the outer pit supporting structure.

(2) The surface settlement mainly occurs during the outer excavation. The surface settlement caused by the outer excavation accounts for $70 \%$ of the total settlement. During the excavation of the inner pit, the settlement value of most of the measuring points tended to be stable. However, when the inner pit was excavated to the design elevation of the bottom of the pit, as the construction speed slowed down, the exposure time of the soil at the bottom of the pit increases, causing a further increase in surface settlement. During construction of the bottom of the pit, plain concrete cushions should be poured in time to reduce the exposure time and degree of disturbance of the soil.

(3) Under the influence of the corner effect, the maximum settlement of the corner position was furthest away from the wall. The simulation results further reflected the existence of the corner effect, which caused fluctuations in the settlement value within 0.8 times of the excavation depth behind the wall. By plotting the normalized maximum settlement and the distance behind the wall, it can be concluded that the simulation results and the measured values were small. In addition, the data points fell within the range of zone I (sand and soft-to-hard clay), as summarized by Peck.

(4) During the entire excavation process, the strut force of each layer increased with an increase in the excavation depth, and the axial force of the bottom support changed most significantly. It can be found by drawing the apparent earth pressure diagram that, for the PIP excavation in the local area, it is more reasonable to use $0.3 \gamma \mathrm{H}_{e}$ as the upper limit index of the strut axial force. When this value is exceeded, engineers should be vigilant and be prepared to take reinforcement measures.

\section{Data Availability}

The data used to support the findings of this study are available from the corresponding author upon request.

\section{Conflicts of Interest}

The authors declare that there are no conflicts of interest regarding the publication of this paper.

\section{Acknowledgments}

This work was supported by the National Natural Science Foundation of China (Grant no. 51878005).

\section{References}

[1] K. Terzaghi and R. B. Peck, Soil Mechanics in Engineering Practicep. 729, 2nd edition, John Wiley \& Sons, New York, NY, USA, 1967.

[2] R. B. Peck, "Deep excavations and tunneling in soft ground," in Proceedings of the 7th International Conference on Soil Mechanics and Foundation Engineering, pp. 225-290, Mexico City, Mexico, 1969.

[3] J. Shi, Z. Fu, and W. Guo, "Investigation of geometric effects on three-dimensional tunnel deformation mechanisms due to basement excavation," Computers and Geotechnics, vol. 106, pp. 108-116, 2019. 
[4] A. T. C. Goh, W. G. Zhang, and K. S. Wong, "Deterministic and reliability analysis of basal heave stability for excavation in spatial variable soils," Computers \& Geotechnics, vol. 108, pp. 152-160, 2019.

[5] A. T. C. Goh, Z. Fan, W. G. Zhang et al., "Assessment of strut forces for braced excavation in clays from numerical analysis and field measurements," Computers \& Geotechnics, vol. 86, pp. 141-149, 2017.

[6] W. Zhang, Z. Hou, A. T. C. Goh et al., "Estimation of strut forces for braced excavation in granular soils from numerical analysis and case histories," Computers and Geotechnics, vol. 106, pp. 286-295, 2019.

[7] Z.-Z. Wang, S. H. Goh, C. G. Koh, and I. F. C. Koh, "An efficient inverse analysis procedure for braced excavations considering three-dimensional effects," Computers and Geotechnics, vol. 107, pp. 150-162, 2019.

[8] M. N. Houhou, F. Smith, and A. Belounar, "Three-dimensional numerical back-analysis of a monitored deep excavation retained by strutted diaphragm walls," Tunnelling and Underground Space Technology, vol. 83, pp. 153-164, 2019.

[9] S. Y. Lam, S. K. Haigh, and M. D. Bolton, "Understanding ground deformation mechanisms for multi-propped excavation in soft clay," Soils and Foundations, vol. 54, no. 3, pp. 296-312, 2014.

[10] G. C. Yan, Research on deformation and stability of foundation pits and analysis method of earth pressure on retaining structures, Tsinghua University, Ph.D. thesis, 2017.

[11] Z. W. Wang, C. W. W. Ng, and G. B. Liu, "Characteristics of wall deflections and ground surface settlements in Shanghai," Canadian Geotechnical Journal, vol. 42, no. 5, pp. 1243-1254, 2005.

[12] Y. Hong, C. W. W. Ng, G. B. Liu, and T. Liu, "Three-dimensional deformation behaviour of a multi-propped excavation at a "greenfield" site at Shanghai soft clay," Tunnelling and Underground Space Technology, vol. 45, pp. 249-259, 2015.

[13] D. P. Li and C. H. Yan, "Building deformation prediction based on ground surface settlements of metro-station deep excavation," Advances in Civil Engineering, vol. 2018, Article ID 6050353, 14 pages, 2018.

[14] Y. Hong and C. W. W. Ng, "Base stability of multi-propped excavations in soft clay subjected to hydraulic uplift," $\mathrm{Ca}$ nadian Geotechnical Journal, vol. 50, no. 2, pp. 153-164, 2013.

[15] G. B. Ng, R. J. Jiang, C. W. W. Ng, and Y. Hong, "Deformation characteristics of a $38 \mathrm{~m}$ deep excavation in soft clay," $\mathrm{Ca}$ nadian Geotechnical Journal, vol. 48, no. 12, pp. 1817-1828, 2011.

[16] G. B. Liu, C. W. W. Ng, and Z. W. Wang, "Observed performance of a deep multistrutted excavation in Shanghai soft clays," Journal of Geotechnical and Geoenvironmental Engineering, vol. 131, no. 8, pp. 1004-1013, 2005.

[17] C. W. W. Ng, Y. Hong, G. B. Liu et al., "Ground deformations and soil-structure interaction of a multi-propped excavation in Shanghai soft clays," Géotechnique, vol. 62, no. 10, pp. 907-921, 2012.

[18] M. S. Pakbaz, S. Imanzadeh, and K. H. Bagherinia, "Characteristics of diaphragm wall lateral deformations and ground surface settlements: case study in Iran-Ahwaz metro," Tunnelling and Underground Space Technology, vol. 35, pp. 109121, 2013.

[19] D. Twine and H. Roscoe, Temporary Propping of Deep Excavations-Guidance on Design, CIRIA, London, UK, 1999.

[20] A. Alipour and A. Eslami, "Design adaptations in a large and deep urban excavation: case study," Journal of Rock Mechanics and Geotechnical Engineering, vol. 11, no. 2, pp. 389-399, 2019.

[21] Y. Sun, D. L. Zhang, Q. Fang et al., "Research of prediction method for surface subsidence of pit-in-pit projects in Beijing area," Chinese Journal of Rock Mechanics and Engineering, vol. 34, pp. 3491-3498, 2015.

[22] X. Y. Hou, Y. L. Lin, B. F. Xue et al., "Sensitivity analysis of the influence of pit toe coefficient on pit in pit deformation," Chinese Journal of Underground Space and Engineering, vol. 13, pp. 257-263, 2017.

[23] T. C. Han, L. X. Xie, and Z. Liu, "Calculation of passive earth pressure for finite soil in foundation pit under pit-in-pit condition," Rock and Soil Mechanics, vol. 39, pp. 4404-4412, 2018.

[24] X. Shi, C. X. Rong, H. Cheng et al., “An energy solution for predicting buried pipeline response induced by tunneling based on a uniform ground movement model," Mathematical Problems in Engineering, vol. 2020, Article ID 7905750, 12 pages, 2020.

[25] R. B. J. Brinkgreve and W. Broere, Plaxis Material Models Manual, PLAXIS, Delft, Netherlands, 2006.

[26] W. D. Wang, H. R. Wang, and Z. H. Xu, "Experimental study of parameters of hardening soil model for numerical analysis of deep excavations of foundation pits," Rock and Soil Mechanics, vol. 33, no. 8, pp. 2283-2290, 2012.

[27] J. Janbu, "Soil compressibility as determined by oedometer and triaxial tests," in Proceedings of the 3rd European Conference on Soil Mechanics and Foundation Engineering, Wiesbaden, Germany, 1963.

[28] M. D. Bolton, "The strength and dilatancy of sands," Géotechnique, vol. 36, no. 1, pp. 65-78, 1986.

[29] Ministry of Housing and Urban-Rural Development of the People's Republic of China, Code for Monitoring Measurement of Urban Rail Transit Engineering, Ministry of Housing and Urban-Rural Development, Beijing, China, 2013.

[30] W. Li, Braced excavation in old alluvium in Singapore, Nanyang Technological University, Ph.D. thesis, 2001. 